\title{
Plasma-Assisted Ignition and Combustion
}

\author{
Andrey Starikovskiy ${ }^{1}$ and Nickolay Aleksandrov ${ }^{2}$ \\ 1 Princeton University \\ ${ }^{2}$ Moscow Institute of Physics and Technology \\ 1 USA \\ ${ }^{2}$ Russia
}

\section{Introduction}

The history of application of thermally-equilibrium plasma for combustion control started more than hundred years ago with IC engines and spark ignition systems. The same principles still demonstrate high efficiency in different applications. Recently particular interest appears in non-equilibrium plasma for ignition and combustion control [Starikovskii, 2005; Starikovskaia, 2006]. The reason of the interest rise is new possibilities for ignition and flame stabilization which are proposed by plasma-assisted approach. Over the last decade, significant progress has been made in understanding the mechanisms of plasma-chemistry interaction, energy redistribution in discharge plasma and nonequilibrium initiation of combustion. Wide range of different fuels has been examined using different types of discharges.

There are several mechanisms to affect a gas when using a discharge to initiate combustion or stabilize a flame. There are two thermal mechanisms: 1) gas heating due to energy release leads to an increase in the rates of chemical reactions; 2) inhomogeneous gas heating generates flow perturbations and provokes turbulization and mixing. Non-thermal mechanisms include 3) the effect of ionic wind (momentum transfer from electric field to the gas due to space charge-electric field interaction); 4) the ion and electron drift in the electric fields can lead to the additional fluxes of active radicals in the gradient flows; and 5) excitation, dissociation and ionization of the gas by electron impact leads to the nonequilibrium radical production and changes the kinetic mechanisms of ignition and combustion. These mechanisms combined together or separately can provide an additional authority to combustion control which is necessary for ultra-lean flames, high-speed flows, cold low-pressure conditions of high-altitude GTE relight, detonation initiation in pulsed detonation engines, distributed ignition control in HCCI engines and so on.

But, of course, the main interest in plasma technologies is connected with extreme conditions like hypersonic aviation. A hypersonic aircraft that cruises at Mach 6 speed and $30 \mathrm{~km}$ altitude could travel 13,000 km in slightly over 2 hours, including the time needed for takeoff, ascent, descent and landing [Bowcutt, 2009]. This is significant because almost all major world city-pairs are separated by no more than $10,000-12,000 \mathrm{~km}$. It is assumed that the ability to travel such long distances in a short time would be valuable for the delivery of time-critical cargo and for the relatively small percentage of passengers.

The advantage of short flight time, high speed and altitude would be promising to military aircraft and missiles. An air-breathing hypersonic vehicle operates in multiple engine cycles 
and modes to reach scramjet operating speeds and could be used for the development of a space transportation system that would allow cheap and flexible access to space. A typical air-breathing hypersonic flight corridor with operation limits is presented in Figure 1 [Andreadis, 2005].

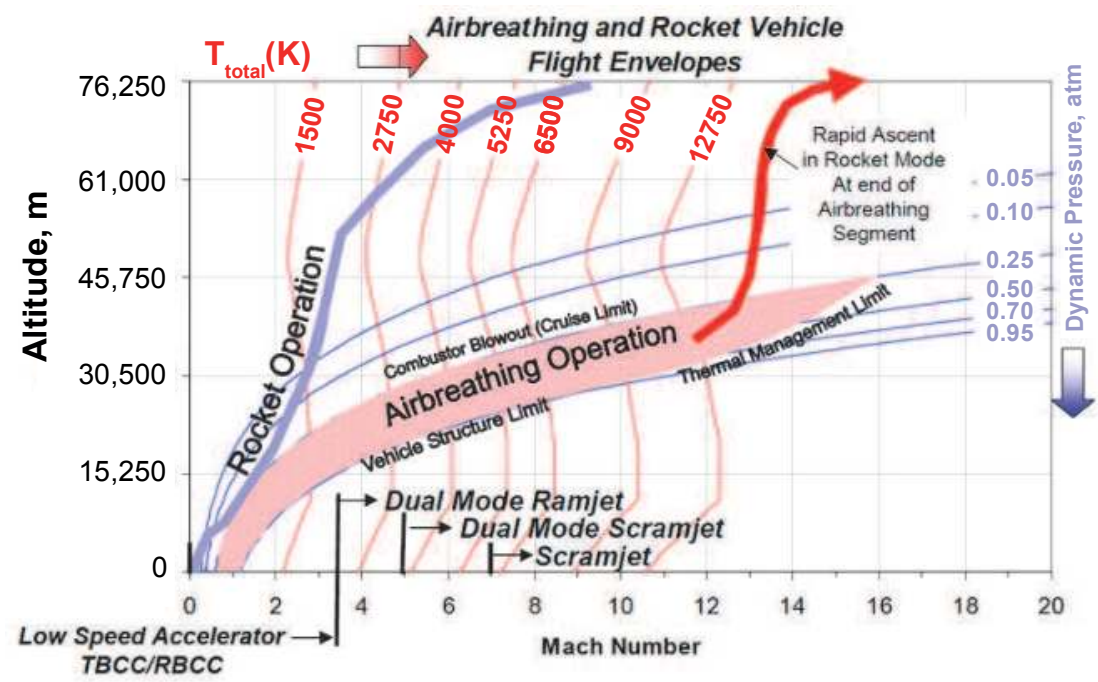

Fig. 1. Air-breathing hypersonic vehicle flight trajectory and operational limits [Andreadis, 2005].

Design challenges are dictated by flight conditions that become increasingly severe due to the combination of internal duct pressure, skin temperature, and dynamic pressure loading [Fry, 2004]. These constraints combination creates a narrow corridor of possible conditions suitable for flight based on ram air compression. The lower boundary of this envelope is set by thermal and structural limitations and is typically limited by a dynamic pressure of about $1 \mathrm{~atm}$.

Relatively high dynamic pressure $q$ is required, compared to a rocket, to provide adequate static pressure in the combustor. The upper boundary is characterized as a region of low combustion efficiency and narrow fuel/air ratio ranges thereby is restricted by combustion stability in the engines (dynamic pressure limit is $0.25-0.5 \mathrm{~atm}$ ).

The high Mach number $(M>15)$ edge of the envelope is a region of strong leading shock waves, with strong dissociation and ionization of the gas in the shock layer. Here, nonequilibrium flow can influence compression ramp flow, induce large leading-edge heating rates, and reduce the efficiency of fuel injection and mixing and combustion. This lead to dramatic performance decrease and puts another limitation on the possible flight envelope for air-breathing hypersonic vehicles. On the contrary, at very low Mach numbers $(\mathrm{M}<3)$ the compression ratio due to flow deceleration is not enough for efficient ramjet operation.

That is why in the low-speed regime $(\mathrm{M}=0-3)$ the vehicle may utilize one of several possible propulsion cycles such as a Turbine Based Combined Cycle (TBCC) with a bank of gas turbine engines in the vehicle, or Rocket Based Combined Cycle (RBCC), with integrated 
rockets, internal or external to the engine, to accelerate the vehicle from takeoff to $M \sim 3$ (Figure 2). Above this point only ramjet/scramjet cycle can propose efficient operation.

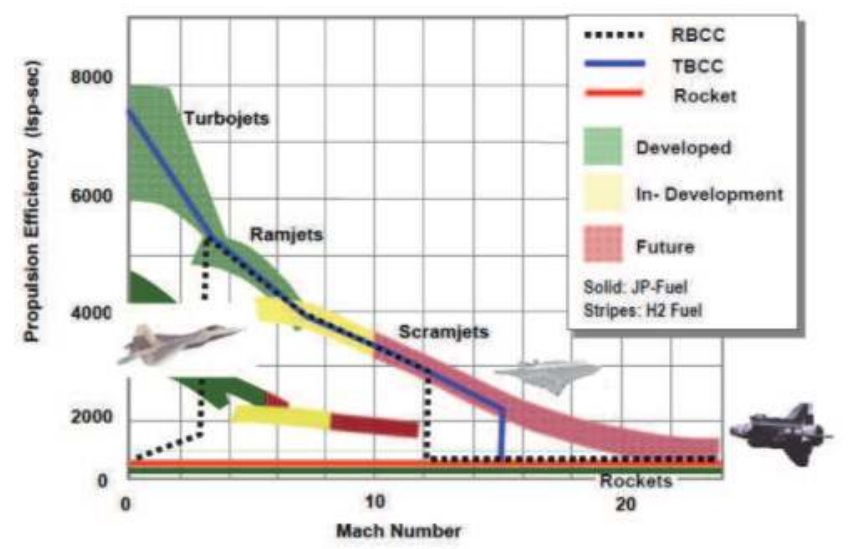

Fig. 2. Propulsion efficiency and operating regimes [Andreadis, 2005]

The concept of scramjet is rather simple; (i) it has a shaped duct with an air inlet at its front end and (ii) a constant-area or slightly divergent section where fuel is injected, mixed, and burned. The section sharply diverges at its aft end to form internal and external nozzles. Expansion of combustion products through the nozzle creates the thrust (Figure 3). The proper shaping of the duct to provide efficient air compression, fuel-air mixing and combustion, and gas expansion is a challenging task. To maximize the overall scramjet performance, the duct should operate in concert with the vehicle upon which it is integrated [Bowcutt, 2009]. This integration should take into account material limitations, fuel characteristics, range of speed, flight attitude, and atmospheric pressure.

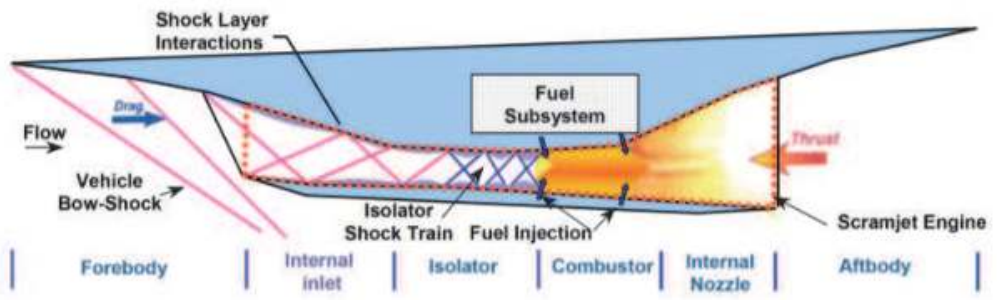

Fig. 3. Air-breathing supersonic combustion ramjet (scramjet), which provides a means of efficient hypersonic propulsion [Bowcutt, 2009].

The scramjet engine can operate as a dual-mode ramjet in the Mach 3 to 6 regime along the isolator capability limit to avoid inlet unstart and to remain within the structural limits (Figure 2) [Andreadis, 2005]. As the vehicle continues to accelerate beyond Mach 7, the combustion process is unable to separate the flow and the engine operates in scramjet mode 
with a pre-combustion shock-free isolator. The inlet shocks propagate through the entire engine.

The efficiency of scramjet operation depends crucially on the efficiency and completeness of combustion process; low efficiency of combustion restricts the upper boundary of the flight envelope. Plasma assisted combustion is a promising way to stabilize ignition at high altitudes and at low dynamic pressures and temperatures (Figure 1). On the other hand, plasma assisted ignition can stabilize ultra-fast combustion that is required for $M>10$ operations (Figure 2). Thus, the ultimate goal of plasma methods in hypersonic applications is an extension of the engine stability region to low dynamic pressures (0.2-0.05 atm) and to high Mach numbers $(\mathrm{M}=10-20)$.

A review of recent experimental studies of non-equilibrium plasma assisted ignition and combustion is given in [Starikovskaia\&Starikovskii, 2011]. There is also a detailed review of experimental and theoretical work in this field for $\mathrm{H}_{2}-\mathrm{O}_{2}$ mixtures [Popov, 2007]. Over the last years, considerable progress has been made in the understanding of the mechanisms of plasma assisted combustion in various mixtures including hydrocarbon-containing ones. The mechanisms were validated by making experiments under controlled conditions and by comparing the results with numerical simulation of discharge and combustion processes. The purpose of this work is to review the modern state-of-art in this area. We consider possibilities to generate chemically active discharge plasma with desirable parameters and mechanisms of the effect of non-equilibrium plasma on ignition and combustion. The difficulties in studies and unsolved problems are discussed. The number of works devoted to plasma assisted combustion is too large. Therefore, this survey does not tend to cite all available papers. Instead, we attempt to present only new results and to show the main obstacles for further progress in the use of non-equilibrium plasma in favoring combustion processes.

\subsection{Demonstration of efficiency of plasma assisted combustion}

There have been many impressive demonstrations of plasma-assisted ignition (PAI) advantages over the last decade [Starikovskii, 2005; Starikovskaia, 2006]. Control of ignition and combustion in fast gas flows is important since it is applicable for aircraft jet engines, where the problems of reduction of ignition delay time, of high-altitude flameholding and of extension of flame blow-off limits are of crucial importance. Plasma assisted ignition and flame holding in aerospace applications should cover an extremely wide range of parameters. The temperature range corresponds to regimes from high-altitude re-light $(\sim 220 \mathrm{~K})$ to a full-load mode after gas compression $(\sim 800 \mathrm{~K})$ and flame stabilization in afterburner $(\sim 1200 \mathrm{~K})$. The pressure range is $0.1-10 \mathrm{~atm}$, whereas the flow velocity is in the range $100-1000 \mathrm{~m} / \mathrm{s}$. Mixture composition varies from lean to rich in different locations. Here, we will mention some recent results only to demonstrate the progress under different flow conditions.

\subsubsection{Supersonic flows}

The paper [Leonov et al, 2011] studied particular mechanisms of the plasma effect on highspeed combustion. The TDLAS (tunable diode laser absorption) technique was applied for detection of temperature and $\mathrm{H}_{2} \mathrm{O}$ concentration in the combustion zone of a supersonic $(\mathrm{M}=2)$ air-fuel flow. Hydrogen and ethylene injected directly through the wall were used as a fuel. The combustion process was initiated and sustained by a near-surface electric discharge. 
The discharge appeared in the form of oscillating plasma filaments as it is shown in Fig.4a, b. Initially, electrical breakdown occured near the electrodes. The individual filaments were blown down due to the main flow with velocity that was a bit less than the core velocity. The frequency of oscillations depended on flow speed, inter-electrode gap, and parameters of the power supply. In most cases this frequency was $f=10-30 \mathrm{kHz}$. Plasma power was in a range of $W_{\mathrm{pl}}=3-17 \mathrm{~kW}$. Special experimental series showed a generation of sequence of active zones of reacting gas moving downstream from the place of immediate plasma-fuel interaction (see Figure 4).

Ignition in a supersonic propane-air flow at $\mathrm{M}=2$ by a microwave discharge was reported in [Shibkov1,2]. The ignition was detected as a strong emission in the visible region of spectrum in the aerodynamic channel downstream of the discharge section. The induction time was simultaneously derived from different measurements, such as the control of $\mathrm{CH}$ emission at $431 \mathrm{~nm}$, the measurements of the electric current through a plane capacitor at the outlet of the channel, and the control of output signal with an acoustic noise meter. The authors analyzed a direct current discharge $(E / N=10-30 \mathrm{Td})$, a pulse-periodic electrode transversal discharge $(30-70 \mathrm{Td})$, a freely localized microwave discharge (70$120 \mathrm{Td})$, and a surface microwave discharge (100-200 Td) and concluded that the discharges with higher reduced electric fields give shorter induction times for combustion.
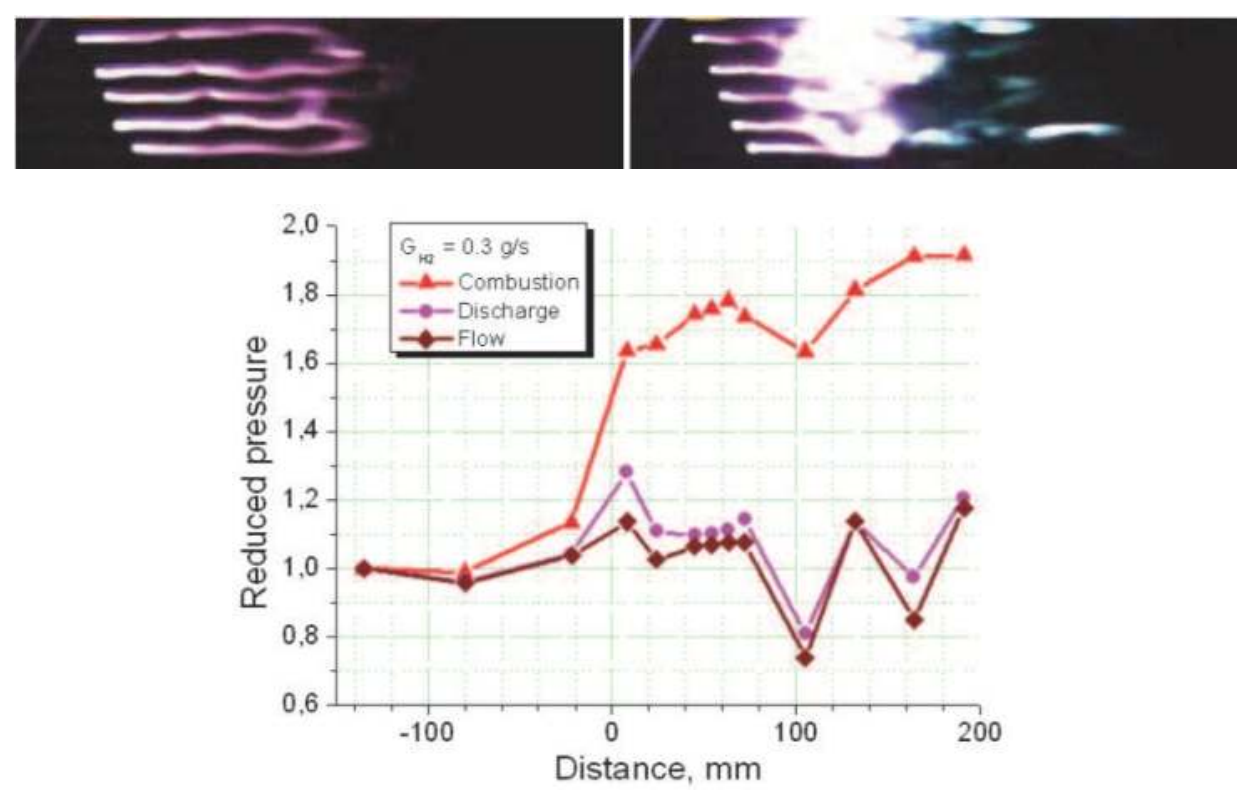

Fig. 4. Discharge appearance: (a) instant photo, flow from left to right; (b) discharge with ethylene injection; (c) evolution of wall pressure at hydrogen injection. Discharge power is $\mathrm{W}_{\mathrm{pl}}=8 \mathrm{~kW} . \mathrm{X}=0$ is the electrode line. $M=2$ [Leonov et al, 2011].

Another typical scheme of the experimental study of PAI in supersonic gas flows [Esakov et al, 2006] is given by Figure 5. The air flowed to the chamber through an $M=2$ supersonic 
nozzle. Fuel or fuel-air mixture was injected through the pylon input. On the basis of temperature measurements, the authors [Esakov et al, 2006] made a conclusion that the combustion of propane-air mixtures occurs in an $\mathrm{M}=2$ gas flow under the action of a microwave discharge with a power up to $200 \mathrm{~W}$.

A nanosecond pulsed discharge located between two fuel jets was used to ignite and hold jet flames in supersonic crossflows, without the use of additional devices (e.g., cavities or backsteps) for flame holding [Do et al, 2010]. The fuel injection nozzles and discharge electrodes were mounted flush with the surface of the flat wall adjacent to the freestream flow. The nonequilibrium plasma was produced by repetitive pulses of $15 \mathrm{kV}$ peak voltage, $10 \mathrm{~ns}$ pulse width and $50 \mathrm{kHz}$ repetition rate. Sonic or subsonic fuel jets (hydrogen and ethylene) were injected into a pure oxygen freestream of Mach numbers $M=1.7-2.4$. The shockwave/flow structures induced by the fuel jets and the $\mathrm{OH}$ radical distribution resulting from combustion were characterized by Schlieren photography and planar laser induced fluorescence imaging, respectively. A configuration combining an upstream subsonic oblique jet and a downstream sonic transverse jet was shown to provide adequate flow conditions for jet flame ignition assisted by the plasma discharge. The experimental results were interpreted using a simple model in which the pulsed plasma served as a source of reactive radicals added to a flammable gas mixture.
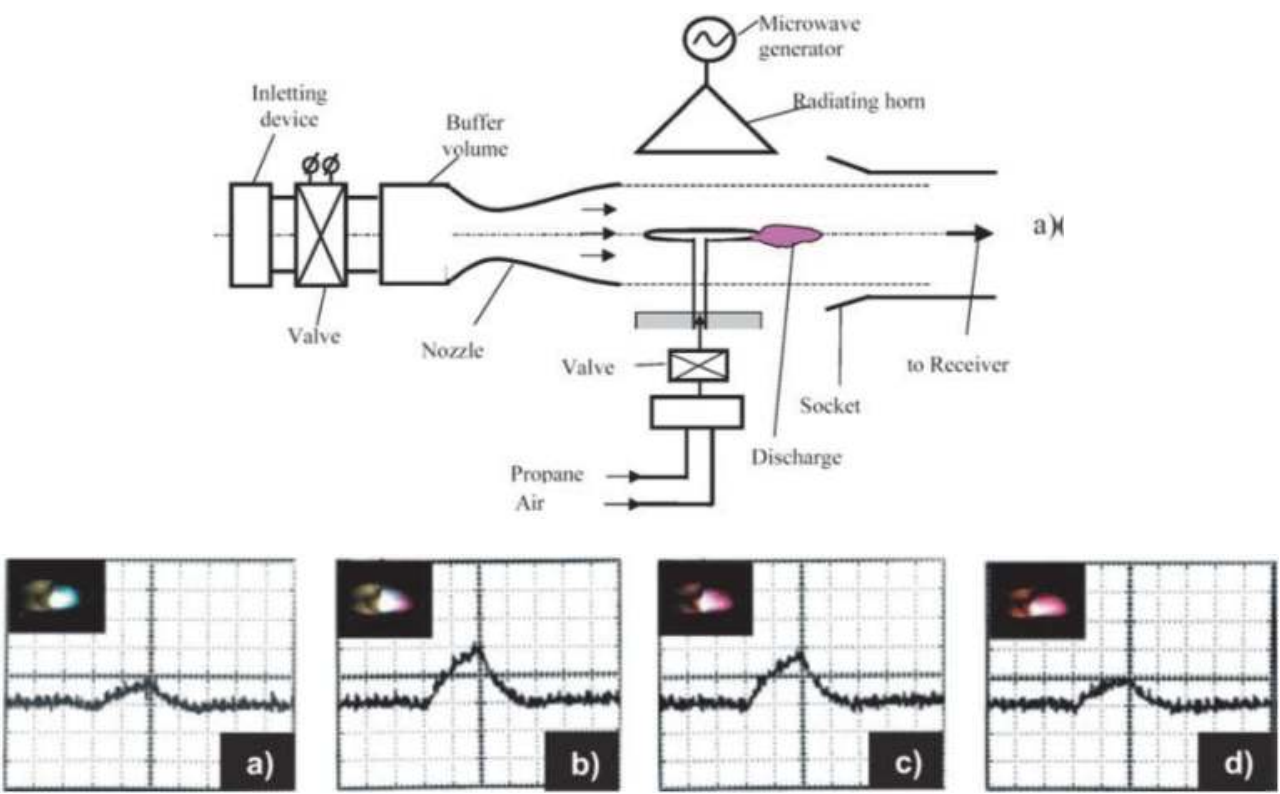

Fig. 5. Scheme of experimental setup for hypersonic microwave ignition (top) and the timeline of operation of experimental setup (bottom). Pressures and temperatures as well as times of discharge and fuel injection are marked in the scheme. Waveforms of stagnation temperature and emission from the discharge during combustion of a propane-air mixture for various air-fuel ratios, $r$. (a) $r=0,(b) r=5.9,(c) r=14.4$, and $(d)$ air flow without propane [Esakov et al, 2006]. 

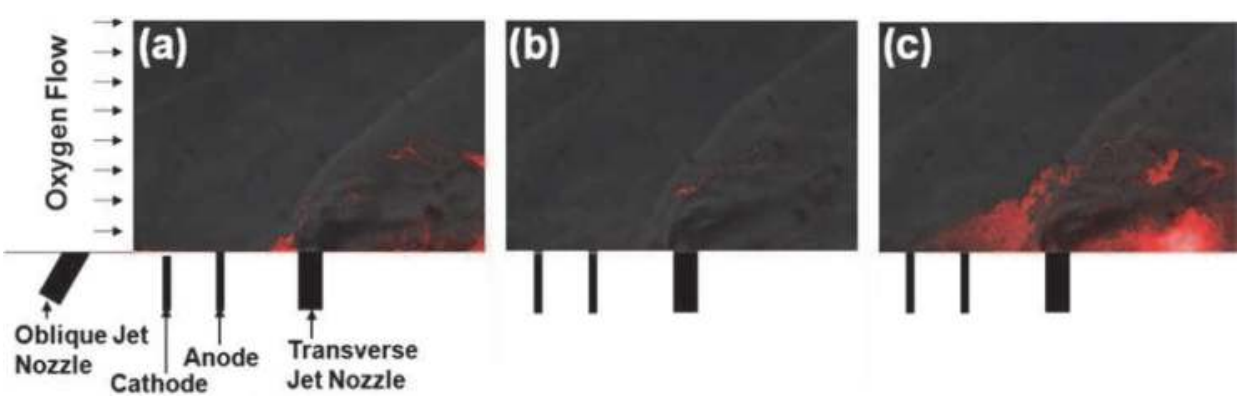

Fig. 6. The OH PLIF images overlapped with a typical Schlieren image of the same flow condition [Do et al, 2010]: (a) without the upstream jet, (b) with both jets active without plasma and (c) in the presence of the plasma with both jets.

Figure 6 depicts OH PLIF images superimposed onto Schlieren photographs with a pure oxygen crossflow. The left panel (Fig. 6a) corresponds to the case without the upstream jet and without the discharge, and the center panel (Fig. 6b) corresponds to the case with both the subsonic upstream and sonic downstream jet active, but without the discharge. In the absence of both the upstream jet and discharge, there is a moderate $\mathrm{OH}$ signal on the windward side of the main sonic jet in the recirculation region near the surface (Fig. 6a), induced by a strong bow shock. However, a rather weak fragmented flame detached from the surface was observed with both the jets activated (Fig. 6b), while the jet flame was significantly enhanced by the discharge plasma as shown in Fig. 6c [Do et al, 2010].

\subsubsection{Subsonic flows}

Experimental studies of the working processes in a low emission gas turbine combustor with plasma assistance have been conducted in [Serbin et al, 2011]. It was shown that the proposed concept of a gas turbine combustor with pilot flame stabilization by nonequilibrium plasma can provide higher performance, wider turn down ratios, and lower emission of carbon and nitrogen oxides. Simulation of the processes in a modified gas turbine combustor showed significant improvements of the combustor temperature distributions and ecological characteristics. Maximum temperature level of the combustion products (Figure 7) were decreased by $190 \mathrm{~K}$ (from 2340 up to $2150 \mathrm{~K}$ ). As the result, the $\mathrm{NO}_{\mathrm{x}}$ emission was reduced from 16 to $1 \mathrm{ppm}$ without increase of carbon monoxide emission.

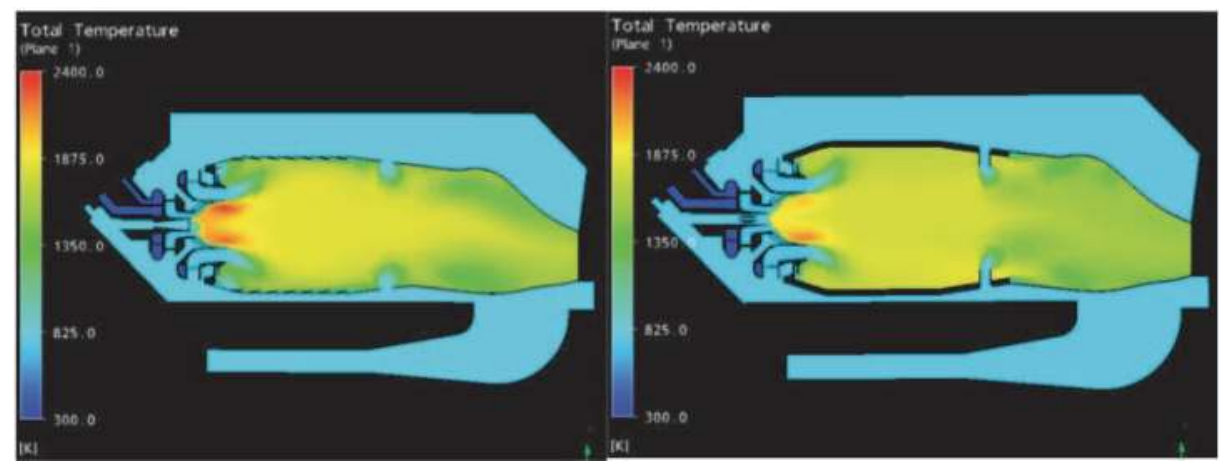

Fig. 7. Temperature field in the combustor: $(a)$ - basic case; $(b)$ - modified [Serbin et al, 2011]. 
A nanosecond repetitively pulsed plasma produced by electric pulses of amplitude $10 \mathrm{kV}$, duration $10 \mathrm{~ns}$ and frequency up to $30 \mathrm{kHz}$ has been used to stabilize and improve the efficiency of a $25 \mathrm{~kW}$ lean turbulent premixed propane/air flame $\left(\operatorname{Re}_{D}=30000\right)$ at atmospheric pressure in [Pilla et al, 2006]. It was show that plasma generation in the recirculation zone of the flow led to a significant increase in heat release and in combustion efficiency., This allowed stabilization of the flame under lean conditions under which it would not exist without the plasma. Stabilization was obtained with a very low level of plasma power, about $75 \mathrm{~W}$ that accounts for $0.3 \%$ of the maximum power of the flame (Figure 8).

The domain of stability of the V-shaped flame without plasma is represented by region 1 in Figure 8. Region 2 represents the extended domain of stability of the V-shaped flame when the plasma is generated. Region 3 corresponds to a regime of intermittent flame, still with a relatively high level of heat release. Region 4 corresponds to the domain of the pilot flame. This pilot flame, being useful in reigniting the combustor, can exist over a much wider range of fuel equivalence ratios and flow rates than that without plasma [Pilla et al, 2006].
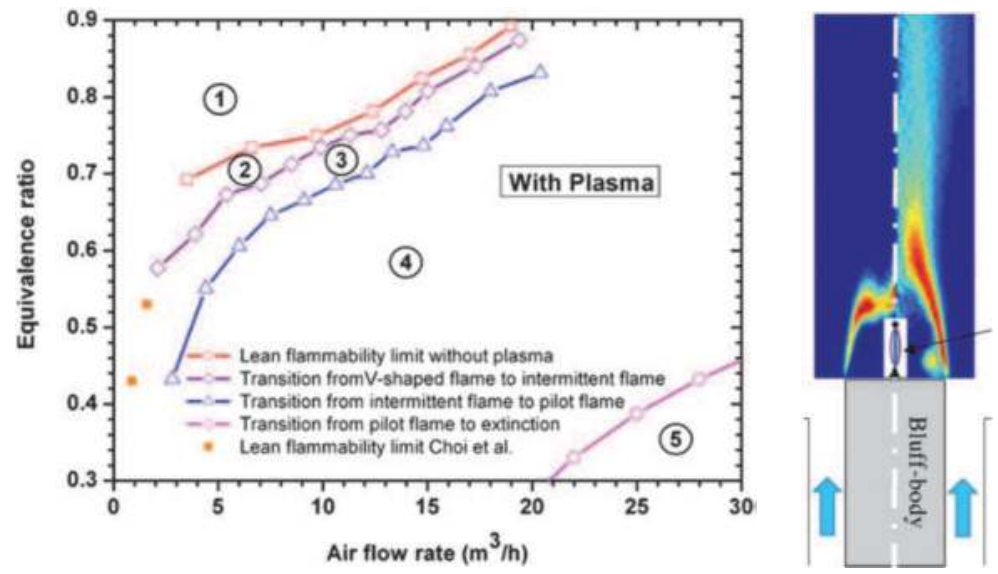

Fig. 8. (a) Burner regimes with plasma in filamentary regime. (b) Comparison of $\mathrm{OH}(\mathrm{A}-\mathrm{X})$ emission with and without discharge. Emission of the plasma was blocked (mask location is shown by arrow). Flame power: $12.5 \mathrm{~kW}$, discharge power: $75 \mathrm{~W}$; air: $14.7 \mathrm{~m}^{3} \mathrm{~h}^{-1}$, propane: $0.5 \mathrm{~m}^{3} \mathrm{~h}^{-1}(\varphi=0.83)$ [Pilla et al, 2006].

\subsubsection{Ignition control in quiescent gas}

Ignition in methane/air mixtures has been achieved using low energy seed laser pulses and an overlapping subcritical microwave pulse [Michael et al, 2010]. It was shown that an extremely weak ionization by a laser localizes the microwave energy deposition and leads to rapid heating, high temperatures, and ignition. Multiple simultaneous localized regions of ignition were also achieved using the same microwave pulse. Interactions of the seed laser pulse and microwave heating pulse were observed using schlieren and shadowgraph to record the intensity of heating and the scale of the interaction and to confirm ignition. In addition, a coupled one-dimensional gasdynamic-plasma dynamic model has been developed to follow the rapidly evolving plasma properties and the gas properties achieved through this interaction. An increase in the femtosecond seed laser pulse energy resulted in 
a significant change in the character of the ignition process. By increasing the pulse energy by a factor of 3 , ignition along the seed laser path was observed. In this case, a much larger region of strong coupling with the microwave can be seen in the shadowgraph images, as shown in Figure 9 [Michael et al, 2010].
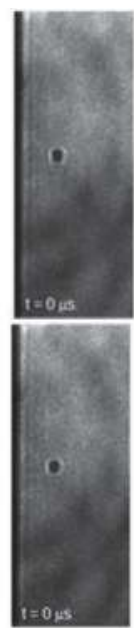
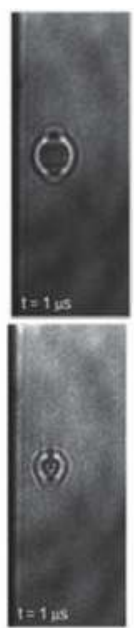
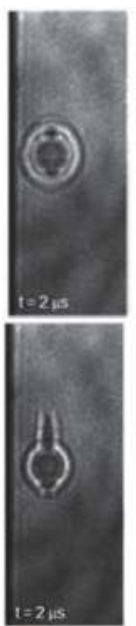
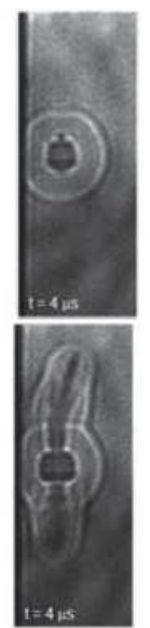
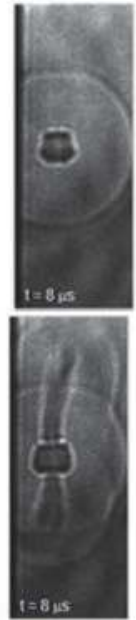
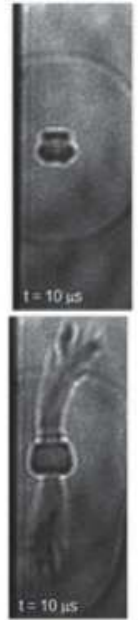
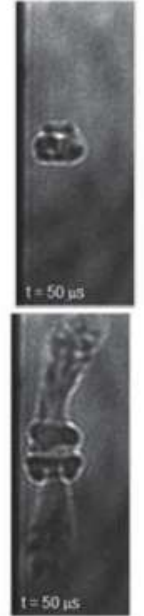
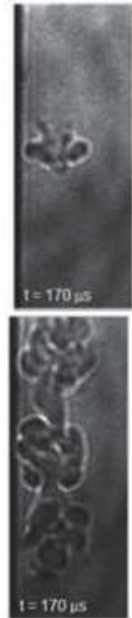

Fig. 9. Ps Laser-MW Evolution in Air. a) Laser spot evolution b) Laser + MW evolution [Michael et al, 2010].
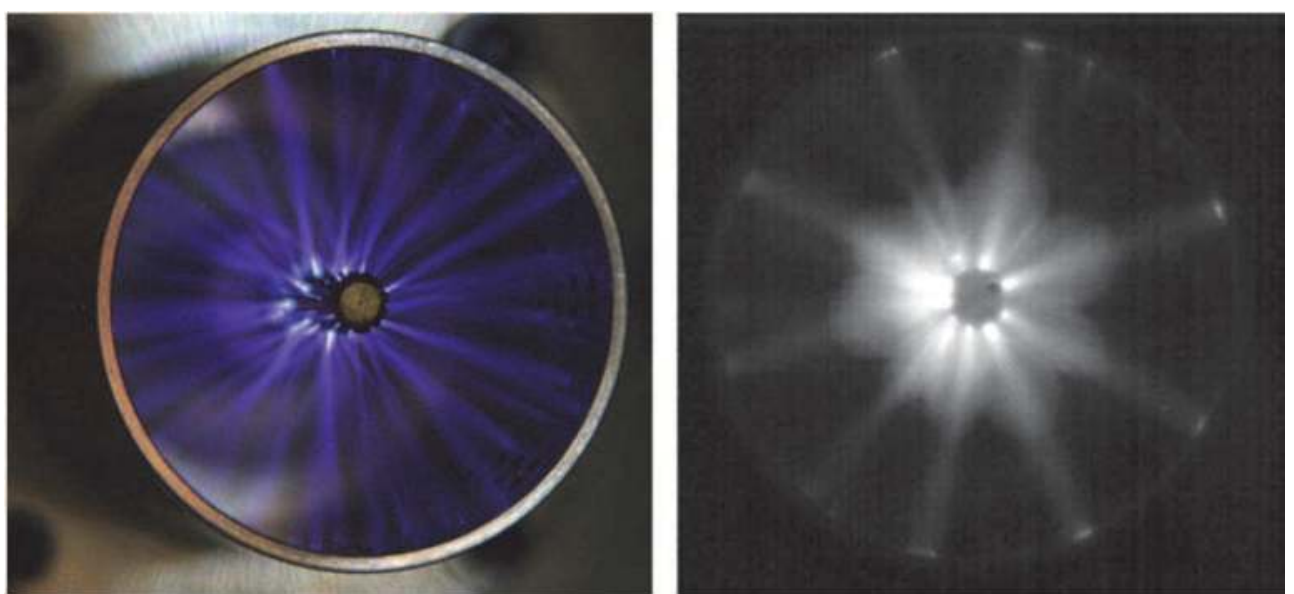

Fig. 10. Left: streamers generated by a single $370 \mathrm{~mJ}, 56 \mathrm{kV}, 54 \mathrm{~ns}$ pulse (maximum $E / n \approx 400$ $\mathrm{Td}$ ) in air (10 s gate time); Right: flame propagation from multiple ignition sites at the base of the streamers after a single pulse in $\varphi=1.1 \mathrm{C}_{2} \mathrm{H}_{4}$-air mixture ( $1 \mathrm{~ms}$ gate time). Both images were captured from the same off-axis angle [Singleton et al, 2011].

Transient plasma ignition, involving short ignition pulses (typically 10-50 ns), has been shown to effectively reduce ignition delays and improve engine performance for a wide 
range of combustion-driven engines relative to conventional spark ignition. Two distinct phases of the plasma-ignition process were demonstrated in [Singleton et al, 2011]: an initial non-equilibrium plasma phase, wherein energetic electrons transfer energy into electronically excited species that accelerate reaction rates, and a spatially distributed thermal phase, that produces exothermic fuel oxidation reactions that result in ignition. It is shown that ignition kernels are formed at the ends of the spatially separated streamer channels, at the cathode and/or anode depending on the local electric field strength, and that the temperature in the streamer channel is close to room temperature up to $100 \mathrm{~ns}$ after the discharge [Singleton et al, 2011].

The results presented in Figure 10 show that after a transient plasma discharge in a $\varphi=1.1$ $\mathrm{C}_{2} \mathrm{H}_{4}$-air mixture at $1 \mathrm{~atm}$, (i) ignition occurred within the streamer channel, (ii) flame initiation occurred within $1 \mathrm{~ms}$ of the discharge and (iii) flame propagation was faster than that initiated by conventional spark ignition. Therefore, when considering the mechanism of ignition via a transient plasma discharge, it is relevant to consider how the energy is deposited and over what timescale, and how that impacts ignition. In these studies, the electrical pulse delivered approximately $70 \mathrm{~mJ}$ to the mixture in $12 \mathrm{~ns}$, distributed across many streamer channels (typically $\approx 50$ ). Therefore, $\sim 1.5 \mathrm{~mJ}$ was applied to the fuel-air mixture in each streamer, which was sufficient for ignition [Singleton et al, 2011].

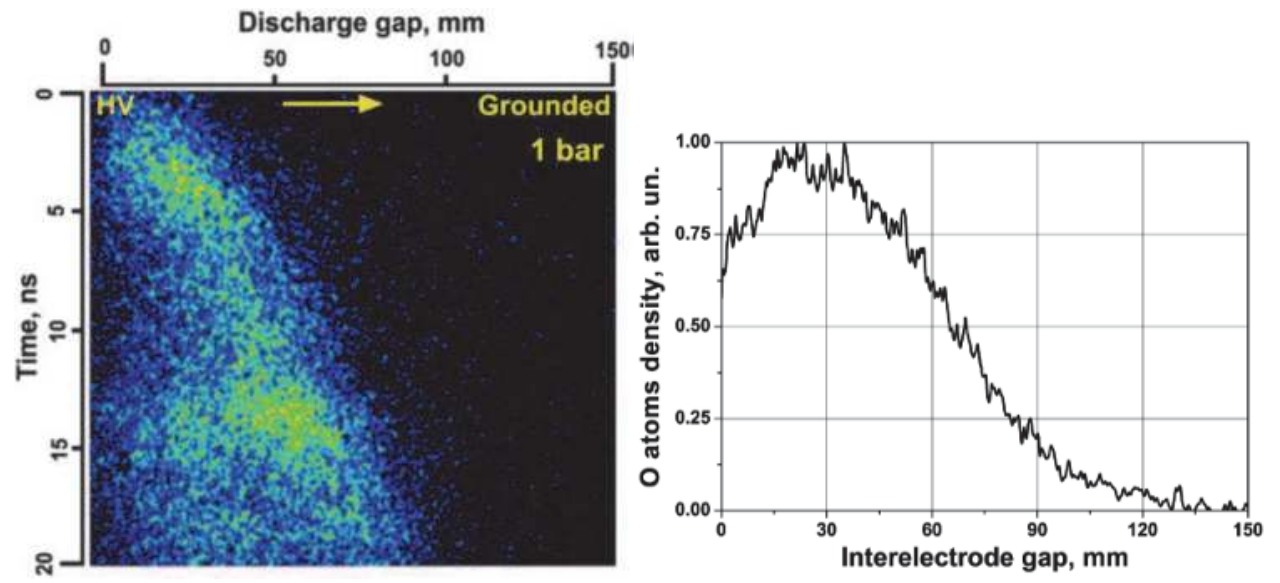

Fig. 11. A) Streak image of discharge development in air at 1 bar. Streamer velocity: 3.5 $\mathrm{mm} / \mathrm{ns}$. B) O atom density distribution over the interelectrode gap [Rakitin et al, 2011].

An experimental study of detonation initiation by high-voltage nanosecond gas discharge has been performed in smooth detonation tubes in [Rakitin\&Starikosvkii, 2008], [Rakitin et al, 2011]. A gradient mechanism was used to initiate detonations in stoichiometric propane-oxygen mixtures with different nitrogen dilution and in propane-air mixtures. Initial pressures from 0.2 to 1 bar have been tested. Detonation was formed within 4 transverse tube sizes at initial pressures higher than 0.2 bar for the propane-oxygen mixture and higher than 0.8 bar for the diluted mixture with $40 \%$ of nitrogen. The discharge energy inputs were $0.2-0.3 \mathrm{~J}$ (Figure 11). The gradient mechanism of 
detonation formation similar to the one suggested by Zeldovich has been shown to be the governing process.

The streamer mode of discharge propagation without the formation of a hot channel resulted in a fast DDT. The results are presented in terms of a time-resolved frame sequence captured with the UltraSpeedStar16 camera in Fig. 12, a and in terms of an $x$ - $t$ diagram in Fig. 12,b. From the IR sensor data, it is seen that the flame front already propagated at the CJ velocity between sensors 1 and 2 (40 and $120 \mathrm{~mm}$ from the discharge tube). The DDT time was amounted to $150 \mu \mathrm{s}$. At the same time, ICCD imaging showed that the ignition did not occur simultaneously over the channel.
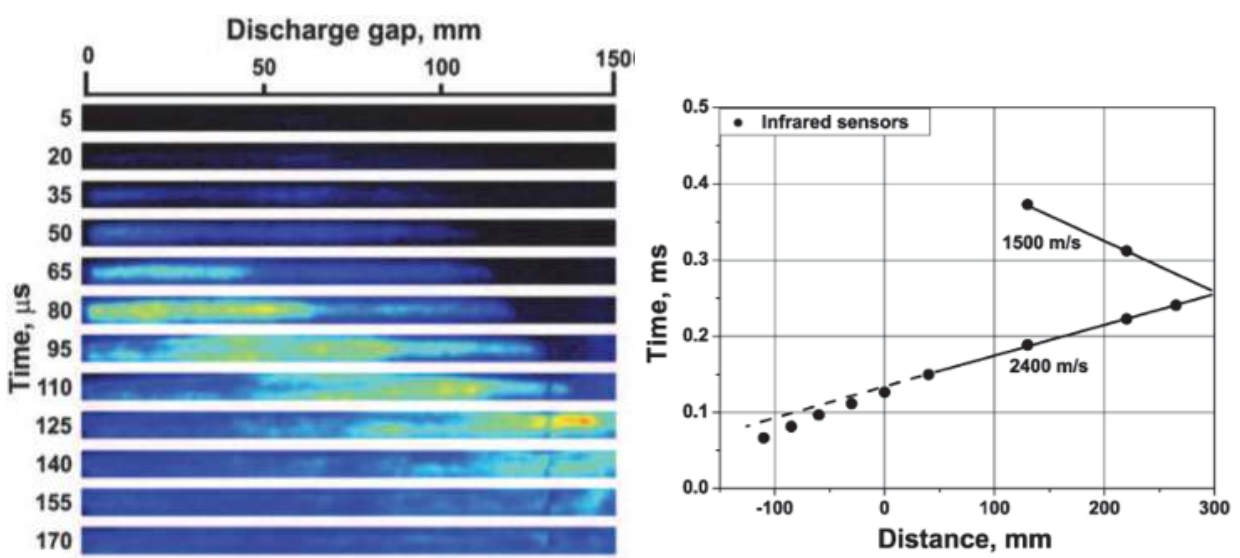

Fig. 12. a) Time-resolved ICCD imaging of fuel mixture ignition inside the discharge chamber. DDT at an initial pressure of 1 bar, streamer mode. b) $x-t$ diagram of DDT at an initial pressure of 1 bar, streamer mode [Rakitin et al, 2011].

A study of pulsed high-voltage nanosecond discharge development in a series of plasmatrons has been conducted in [Nikipelov et al, 2011]. The discharge exhibited three modes of development depending on frequency, voltage and mass flow rate: a surface streamer, a localized spark, and a distributed nonequilibrium transient spark. The plasmatrons developed have been used to stabilize ultra-lean $(f=0.06-0.3)$ flames in a wide range of equivalence ratios and temperatures for methane and diesel vapour at 1 bar. The plasmatrons demonstrated exceptional flame stability with an average discharge power less than $20 \mathrm{~W}$ for a total power of the burner higher than $1 \mathrm{~kW}$ for ultra-lean flame conditions in methane-air mixtures.

Figure 13 shows the discharge development map. Three distinct modes were observed depending on the frequency, voltage and mass flow rate. In a "streamer" mode, the discharge did not bridge the gap mainly due to insufficient pulse voltage. Instead, it developed as a streamer corona starting from the high voltage electrode tip. Under higher voltage, the discharge was either localized at one or two points across the nozzle ("localized spark"), or was distributed over the cross-section ("distributed spark", Figure 13,a), developing as a nonequilibrium transient spark. Each mode was associated with a certain typical value of specific energy input into the discharge, which was measured with the back-current shunt technique. In the streamer mode, a larger part of the pulse was reflected off the discharge gap, while $30 \%$ of the incident energy was deposited into the gas. The 
distributed spark deposited $60 \%$ of the energy on average, whereas the localized spark did $70 \%$. The switching of the modes is shown in Figure 13,b in terms of voltage-frequency $(f-$ $U$ ) maps. Different modes corresponded to different values of specific energy input $E_{i n} / E_{0}$.
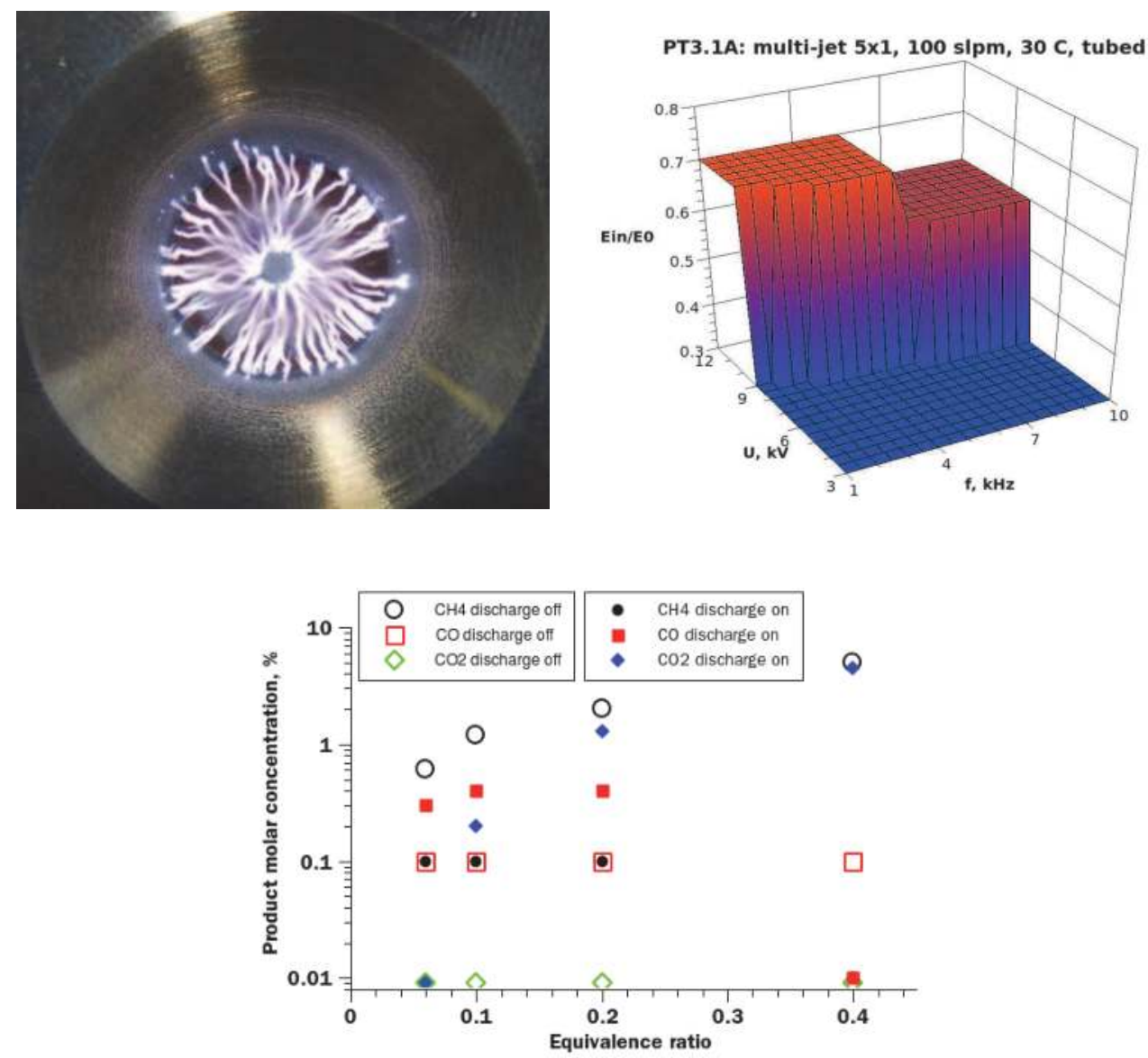

Fig. 13. a) Plasmatron with distributed ns spark. b) Voltage-frequency map of repetitive nanosecond discharge development mode. Inlet air temperature: $300 \mathrm{~K}$. Mass flow rate 100 slpm. c) Plasma-assisted stabilization of premixed methane-air flame. Inlet temperature: $850 \mathrm{~K}$; flow rate: 60 slpm [Nikipelov et al, 2011].

Results for premixed methane-air flow ignition initiation with inlet temperature of $580^{\circ} \mathrm{C}$ in terms of product composition downstream from the burner [Nikipelov et al, 2011] is shown in Figure 13,c. The gas flow rate was $60 \mathrm{slpm}$, the equivalence ratios ranged from 0.06 to 0.4 . For $850 \mathrm{~K}$, it was show that the discharge initiates complete fuel oxidation even for $f=0.06$ (90-95\% of methane was oxidized) into $\mathrm{CO}$ and $\mathrm{CO}_{2}$.

A nanosecond surface barrier discharge was proposed as an igniter at high pressures [Kosarev et al, 2009]. ICCD imaging of a nanosecond DBD in dry 1-5 atm air has been taken. 
Peculiarities of discharge uniformity at different gas pressures were discussed. The ability of the pulsed nanosecond discharge to produce a thin quasi-uniform plasma layer at elevated pressures was demonstrated (Figure 14,a).

a

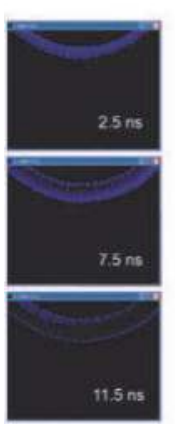

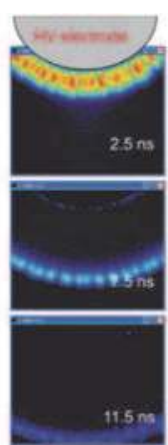

$\mathrm{b}$

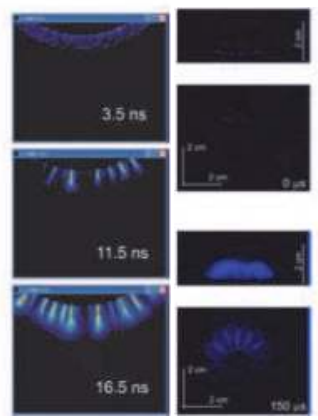

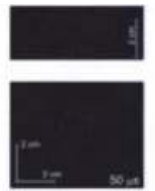

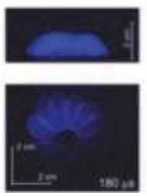

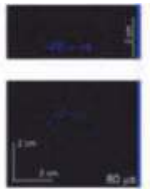
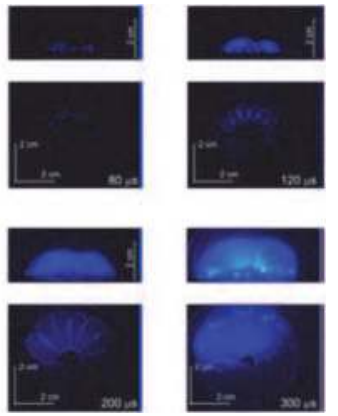

Fig. 14. a) ICCD images of the discharge at $1 \mathrm{~atm}$ dry air. Negative polarity of the highvoltage electrode, $22 \mathrm{kV}, 25 \mathrm{~ns}$ duration, $\phi=40 \mathrm{~Hz}$ [Kosarev et al, 2009]. b) Camera gate is $0.5 \mathrm{~ns}$. Single pulse sliding DBD ignition of $\mathrm{C}_{2} \mathrm{H}_{6}: \mathrm{O}_{2}=2: 7$ mixture at 1 bar and ambient temperature [Sagulenko et al, 2009].

Successful demonstration of high-pressure distributed ignition in a single-pulse SDBD was done in [Sagulenko et al, 2009]. Mixture $\mathrm{C}_{2} \mathrm{H}_{6}: \mathrm{O}_{2}=2: 7$ at 1 bar and ambient initial temperature was successfully ignited in $\sim 100 \mu \mathrm{s}$ in relatively large volume (Figure 14b).

Thus there are successful demonstrations of plasma-assisted ignition and combustion control over very wide range of parameters $-\mathrm{T}=300-1500 \mathrm{~K}, \mathrm{P}=0.1-40 \mathrm{~atm}$, from ultra-lean to reach fuel conditions, flow speed up to $\mathrm{M}=2$. Nevertheless, to scale-up experimental installations we need to know the physical and chemistry underlying. Next section is devoted to mechanisms description which control the plasma assisted ignition and combustion.

\section{Physics of plasma-assisted combustion}

\subsection{Energy branching in discharge plasma}

The major difference between common combustion and plasma assisted combustion is an extremely non-equilibrium excitation of the gas in discharges. In this case, electrons gain energy from an external electric field and transfer this energy through collisions into the various degrees of freedom of other particles. Energy exchange between electrons and translational degrees of freedom of molecules is very slow because of a great difference in masses of the collading particles. This means that electron energy is spent predominantly on the excitation of internal degrees of freedom of molecules. If the rate of internal energy relaxation is not high, the population of the excited states of the molecules is far from the equilibrium energy distribution. Overpopulation of excited states leads to an increase in the system reactivity and facilitates ignition and flame propagation. From this point of view, the most important question for plasma-stimulated chemistry is the discharge energy branching ratios for different degrees of freedom of molecules, rate of system relaxation (thermalization) and chemically-active system response to this non-equilibrium excitation. The rate of molecule excitation by electron impact in discharge plasma depends on the electron energy. The lowest energy is needed for excitation of rotational degrees of freedom. Typical 
spacing between rotational levels of simple molecules is $\sim 10-100 \mathrm{~K}$ and electron energy $\sim 300 \mathrm{~K}$ $(\sim 0.03 \mathrm{eV})$ is enough for efficient rotational excitation. Typical quantum of vibrational degrees of freedom is in the range 1-3 kK. This means that, for efficient vibrational excitation, the average electron energy should be comparable with or higher than this magnitude (in air it should be in the range of $0.2-2 \mathrm{eV}$ ). Excitation of electronical degrees of freedom and molecule dissociation require energies of 3-10 eV. When the average electron energy exceeds $10 \mathrm{eV}$, ionization becomes one of the dominant electron impact processes. Thus the possibility to control the electron energy means the possibility to control the direction of energy deposition and selective excitation of different degrees of freedom of molecules.

Average electron energy in gas discharge is determined by a reduced electric field $E / n$, where $E$ is the electric field and $n$ is the gas number density [Raizer, 1991]. Figure 15 illustrates the deviation of the characteristic electron energy, $\mathrm{D} / \mu$, from the temperature of molecules, $\mathrm{T}$, in different gases. Here, $\mathrm{D}$ is the diffusion coefficient of electrons and $\mu$ is their mobility. The critical $E / n$ for the noticeable difference between $\mathrm{D} / \mu$ and $\mathrm{T}$ and, consequently, for the formation of a non-equilibrium electron energy distribution is close to $E / n \sim 0.1 \mathrm{Td}$ for atomic gases and to $E / n \sim 1 \mathrm{Td}$ for molecular gases $\left(1 \mathrm{Td}=10^{-17} \mathrm{~V} \times \mathrm{cm}^{2}\right)$.

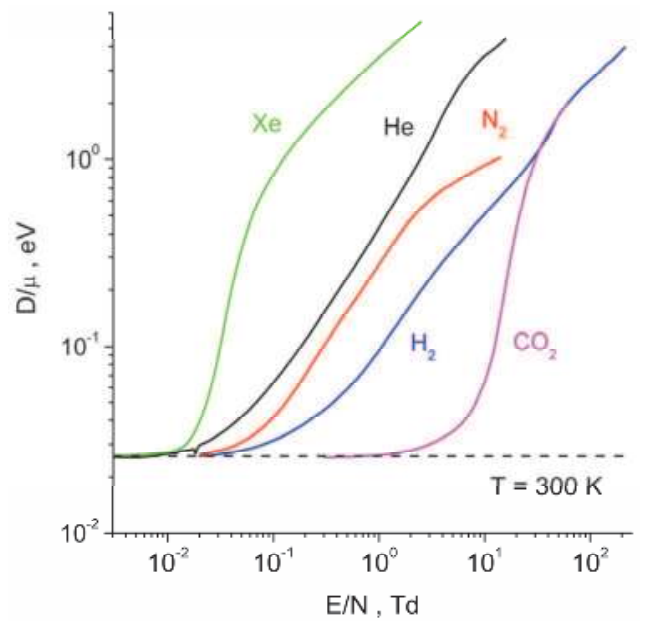

Fig. 15. Characteristic electron energy. He and $\mathrm{Ar}-$ [Dutton, 1975]; $\mathrm{H}_{2}, \mathrm{~N}_{2}$ and $\mathrm{CO}_{2}-$ [Huxley\&Crompton, 1974].

Nonequilibrium electron energy distribution function (EEDF) can be found from a solution of the Boltzmann equation. In the simplest case, the EEDF is time- and space-independent and depends only on the local reduced electrical field, E/n, and gas composition [Babich, 2005]. Further simplification is possible using the so-called two-term approximation in which the EEDF is presented in the form $f(v)=f_{0}(v)+f_{1}(v) \cos \theta$ [Raizer, 1991]), where $v$ is the electron velocity and $\theta$ is the angle between the electron velocity and the ambient electric field.The input data for a solution of the electron Boltzmann equation are the cross-sections of elastic and inelastic collisions between electrons and neutral particles. Figure 16 shows self-consistent sets of electron cross-sections for $\mathrm{CH}_{4}, \mathrm{O}_{2}$ and Ar; electron transport and rate coefficients calculated using these data agree well in the pure gases with available measurements. 


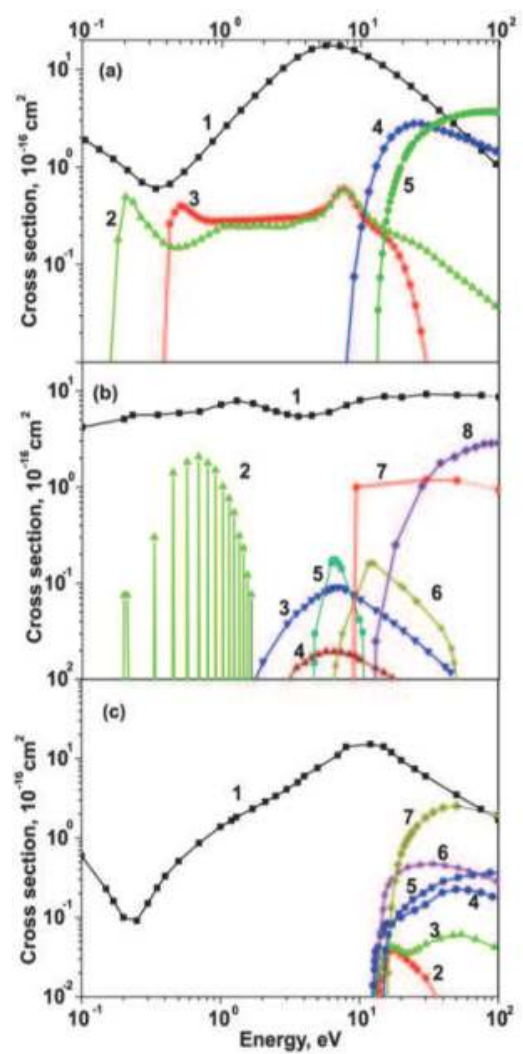

Fig. 16. Electron collision cross sections for (a) $\mathrm{CH}_{4}$ [Hayashi, 1987], (b) $\mathrm{O}_{2}$ [Ionin et al, 2007], and (c) Ar [Tachibana, 1989] as a function of electron energy.

$\mathrm{CH}_{4}$ : (1) momentum transfer in elastic collisions, (2)-(3) vibrational excitation,

(4) electronic excitation, and (5) ionization.

$\mathrm{O}_{2}$ : (1) momentum transfer in elastic collisions, (2) vibrational excitation, (3) excitation of the $a^{1} \Delta_{g}$ electronic state, (4) excitation of the $b^{1} \Sigma_{g}{ }^{+}$electronic state, (5) excitation of the electronic states with $\Delta E=4.5 \mathrm{eV}$, (6) excitation of the electronic state with $\Delta E=6 \mathrm{eV}$,

(7) excitation of the electronic state with $\Delta E=8.4 \mathrm{eV}$, and (8) ionization.

Ar: (1) momentum transfer in elastic collisions, (2) excitation of the ${ }^{1} S_{5}$ electronic state,

(3) excitation of the ${ }^{1} S_{4}$ electronic state, (4) excitation of the ${ }^{1} \mathcal{S}_{2}$ electronic state,

(5) excitation of other allowed electronic states, (6) excitation of other forbidden electronic states, and (7) ionization.

Using the EEDF, it is possible to calculate the energy branching ratios for the different degrees of freedom of neutral particles. Figure 17 demonstrates the calculated fractional power dissipated by electrons into different internal degrees of freedom in various gas mixtures as a function of $E / n$ in discharge plasma. At very low $E / n(\sim 0.1 \mathrm{Td})$ rotational excitation is dominated; here up to $85 \%$ of the discharge energy goes to this excitation. Fast energy exchange between rotational and translational degrees of freedom leads to equilibrium gas heating in this case. An increase of the $E / n$ value to $0.4 \mathrm{Td}$ changes the 
priorities. Above this point the main channel of electron energy dissipation becomes vibrational excitation of oxygen. For reduced electric fileds $4 \mathrm{Td}<E / n<110 \mathrm{Td}$, the most efficient channel of electron energy dissipation in air is vibrational excitation of nitrogen (Figure 17,a). Vibrational-translational (VT) relaxation is a rather slow process at low gas temperatures and the vibrational temperature in discharge plasma could be much higher than the translational one. In the same region of $E / n$,excitation of the lowest electronic level of oxygen, $\mathrm{O}\left(\mathrm{a}^{1} \Delta\right)$ state, takes place. The efficiency of this electronic excitation is very small $(\sim 2 \%)$ in the presence of nitrogen. But a low rate of $\mathrm{O}\left(\mathrm{a}^{1} \Delta\right)$ state oxygen quenching leads to its concentration increase under some conditions. It should be noted that an electric field value $E / n \sim 120 \mathrm{Td}$ is a very important threshold in air. Above this point the electric filed is enough to ionize the gas and discharge can propagate in self-sustained regime. Below this value discharge can exist only in the presence of external source of ionization. At $E / n$ from 140 to $500 \mathrm{Td}$ the main channel of energy losses is excitation of electronic triplet states of nitrogen. Because of high electrons energy in this range of $E / n$ (from 3 to $10 \mathrm{eV}$, correspondingly) ionization of the gas in discharge gap is very fast. Between 500 and $1000 \mathrm{Td}$ the excitation of nitrogen singlet states becomes most important, and above $1000 \mathrm{Td}$ the main portion of the electron's energy goes to ionization of the gas.
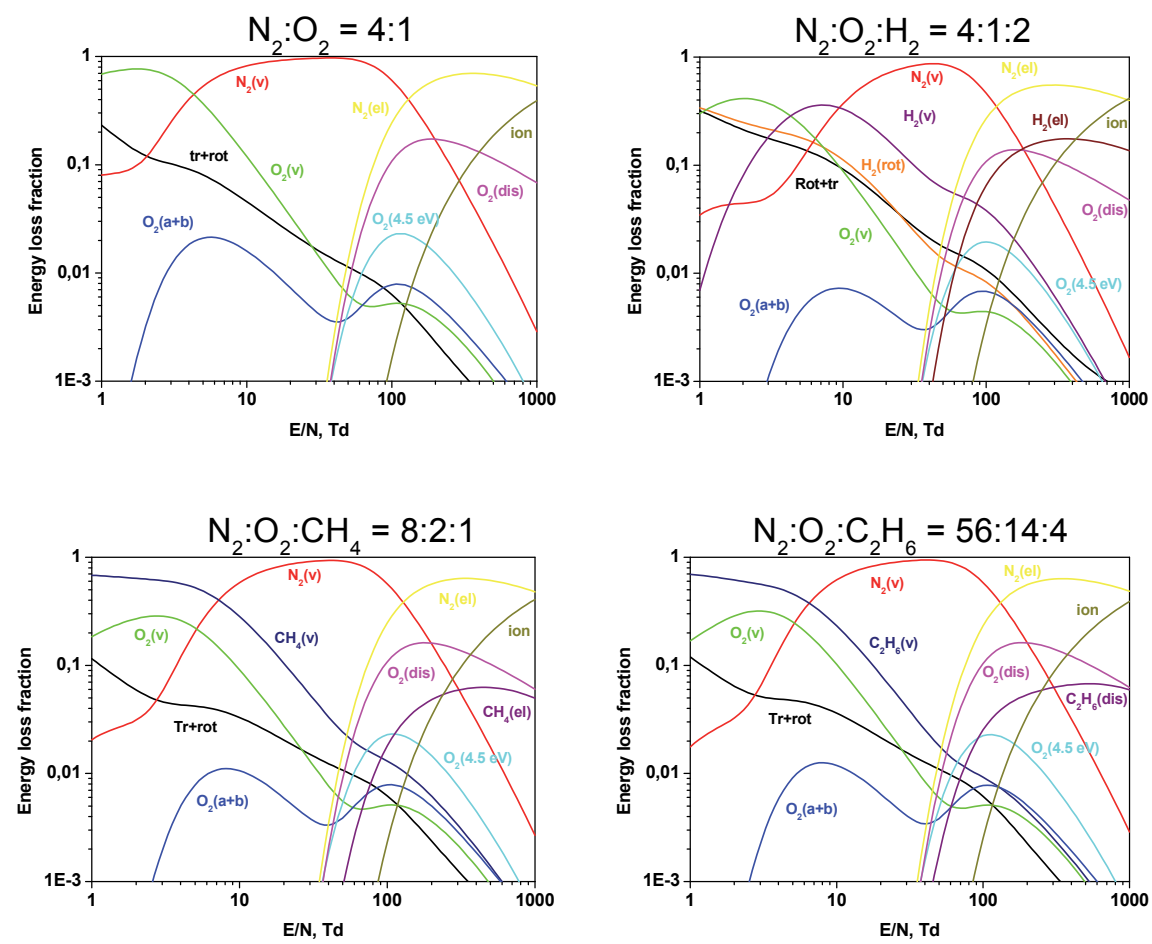

Fig. 17. Fractional power dissipated by electrons into molecular degrees on freedom as a function of $E / n$. (a) Air; (b) $\mathrm{H}_{2}$-Air; (c) Methane-Air; (d) Ethane-Air stoichiometric mixtures. 
Fuel addition in stochiometric ratio (Figures $17(\mathrm{~b}, \mathrm{c}, \mathrm{d})$ ) do not change this picture dramatically. The main reason is relatively small concentration of fuel molecules in the mixtures under typical combustion conditions. Figure $17(\mathrm{~b})$ demonstrates the effect of hydrogen on the electron energy branching. The stoichiometric mixture $\mathrm{H}_{2}$-air $\left(\mathrm{H}_{2}: \mathrm{O}_{2}: \mathrm{N}_{2}=\right.$ $29: 14.5: 56.5)$ contains about $30 \%$ of hydrogen. It is follows from the calculations that these additives only slightly change the energy distribution at moderate and high $E / n>20 \mathrm{Td}$. Excitation of molecular nitrogen remains the main process. Vibrational and electronic excitation and ionization of hydrogen only slightly change the electron energy branching (Figure $17(\mathrm{~b})$ ). At low $E / n<10 \mathrm{Td}$, the effect of hydrogen addition becomes more significant. Vibrational excitation of hydrogen is the main channel of energy dissipation for $E / n=5-10$ $\mathrm{Td}$. The role of rotational excitation of hydrogen is also important and increases the energy flux into rotational and translational degrees of freedom at low $E / n$ (Figure $17(b)$ ). Almost the same picture is obtained in the stochiometric mixtures with hydrocarbon fuels, methane (Fig. 17(c)) and ethane (Fig. 17(d)).

Thus, the reduced electric field is an important parameter for plasma assisted combustion. The $E / n$ value controls the direction of energy deposition in discharge and governs the composition of active particles produced in the discharge plasma.

In the simplest case, $E / n$ is a function of the gas density, applied voltage and geometry of the discharge cell. Ignition and flame stabilization in different engines require different initial conditions. Gas temperature can vary from T $220 \mathrm{~K}$ (high-altitude re-light of the engine) to the value at the end of compression cycle (T 700-800 K) and temperatures corresponded to the combustion stage $(1000-2500 \mathrm{~K})$. Typical gas density varies from $10^{17}-10^{18} \mathrm{~cm}^{-3}$, which corresponds to conditions of hypersonic flight, and may be as high as (1-3) $\times 10^{20} \mathrm{~cm}^{-3}$ for high pressure turbines or in perspective automobile engines. At ambient temperature, this corresponds to a pressure range from a few Torr to tens of bar.

Figure 18 schematically demonstrate the variety of gas discharges. It was mentioned above that the $E / n$ value in the discharge dictates the type of gas excitation. Electron density determines the power density in plasma:

$$
P=q * E=n_{e} \times v_{d r} \times E=n_{e} \times n^{2} \times \mu_{e}(E / n) \times(E / n)^{2}
$$

where $v_{d r}$ - electrons drift velocity in plasma; $\mu_{e}(E / n)$ - electron's mobility at given reduced electric field; $n_{e}$ - electron's concentration. Thus the energy power density in plasma depends on gas density, $E / n$ value, and electrons concentration.

That is why we choose for discharge classification two variables: $E / n$ and $n_{e}$ (Figure 18). It should be noted, however, that the same type of excitation under different conditions (for example, different pressures, initial gas temperatures) could lead to different results. Some types are "mix" of several types of plasma and different zones of these discharges are characterized by different $E / n$ values. Nevertheless we can trace some common discharge features using this classification. Arc discharges develop at relatively low $E / n$. Main direction of energy deposition is rotational excitation of the gas [Raizer, 1991]. Steady-state MW discharges under high-pressure conditions consist of number of filaments of almost equilibrium relatively hot plasma [Raizer, 1991].

Pulsed gliding arks combines during different stages of their development some features of glow discharges and arks. Reduced electric field value changes from $10 \mathrm{Td}$ to $100 \mathrm{Td}$ and gas excitation is not very selective. Both gas heating through fast relaxation of rotational degrees of freedom and molecules dissociation by e-impact are effective. That is why this type of discharge sometimes is called as "warm" plasma [Fridman, 2008]. 
Typical $E / n$ value in DC glow discharge is close to breakdown threshold ( $100 \mathrm{Td}$ in air) and main channels of gas excitation are vibrational and electronic levels population by e-impact [Raizer, 1991]. Streamer discharges (with or without barrier on the electrodes) demonstrate very high $E / n$ value in the front of ionization wave in the streamer head $(E / n \sim 500 \mathrm{Td})$ while in the streamer's channel $E / n$ value is close to 20-30 Td [Pancheshnyi et al, 2005]. That is why in streamer discharge the energy distribution depends on the geometry of the discharge gap, length of the streamer channel etc. Streamer discharge could be formed if we have a significant (1.1-2 times) overvoltage in the discharge gap. Surface dielectric barrier discharge (SDBD) is characterized by even higher $E / n$ because of very short effective inter-electrode gap. High overvoltage leads to significant energy release to gas ionization [Roupassov et al, 2008]. Extremely short high-voltage pulse rise time leads to formation of so-called fast ionization waves (FIW). For limited time (typically several nanoseconds at $\mathrm{n} \sim 1018 \mathrm{~cm}^{-3}$, shorter at higher gas density) it is possible to maintain $E / n$ on the level close or above the run-away threshold $(E / n \sim 2 \mathrm{kTd}$ in air). High-energy electrons are formed in the discharge region providing homogeneous pre-ionization and excitation of the gas. Discharge develops as a uniform ionization wave propagating at the velocity comparable to local speed of light [Pancheshnyi et al, 1999].

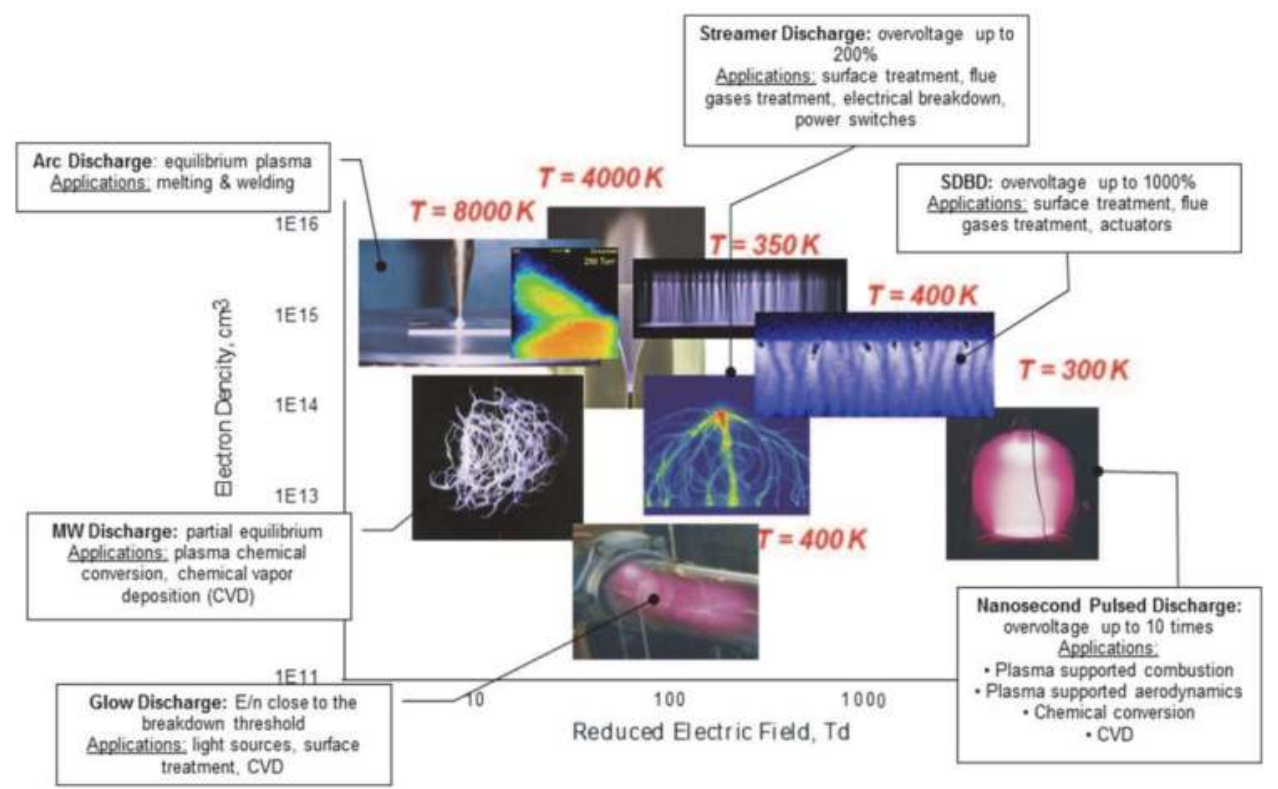

Fig. 18. Discharge development at different overvoltage and plasma generation.

Precise control of the direction of energy deposition in the plasma is possible in relatively short time scale when electrons multiplication (above breakdown threshold) or recombination (below threshold) have no enough time to change electrons concentration and plasma conductivity significantly. When plasma conductivity is not very high it is possible to maintain in inter-electrode gap desired value of $E / n$. This approach together with 
combination of short high-voltage pulse and constant bias allow to provide selective and extremely nonequilibrium excitation of the gas. Critical high-voltage pulse duration depends on the gas parameters (density, composition) but for practically important range of parameters is restricted to few nanoseconds.

Thus the possibility of selective excitation of the gas by electric discharge critically depends on the possibility of ultra-short high-voltage pulses generation. Figure 19 demonstrate recent progress of solid-state generators based on "turn-on" FID and "turn-off" DRD switches according to FID GmbH data [Efanov et al, 2011]. In modern pulsers the pulse rise time goes down to $80 \mathrm{ps}$, voltage rise rate reaches $1 \mathrm{MV} / \mathrm{ns}$, maximal voltage 2-10 MV, and maximal current up to $100 \mathrm{kA}$. Wide range of possibilities proposed by current progress in solid-state electronics will lead to the increase of our abilities of nonequilibrium plasma generation with predicted properties.
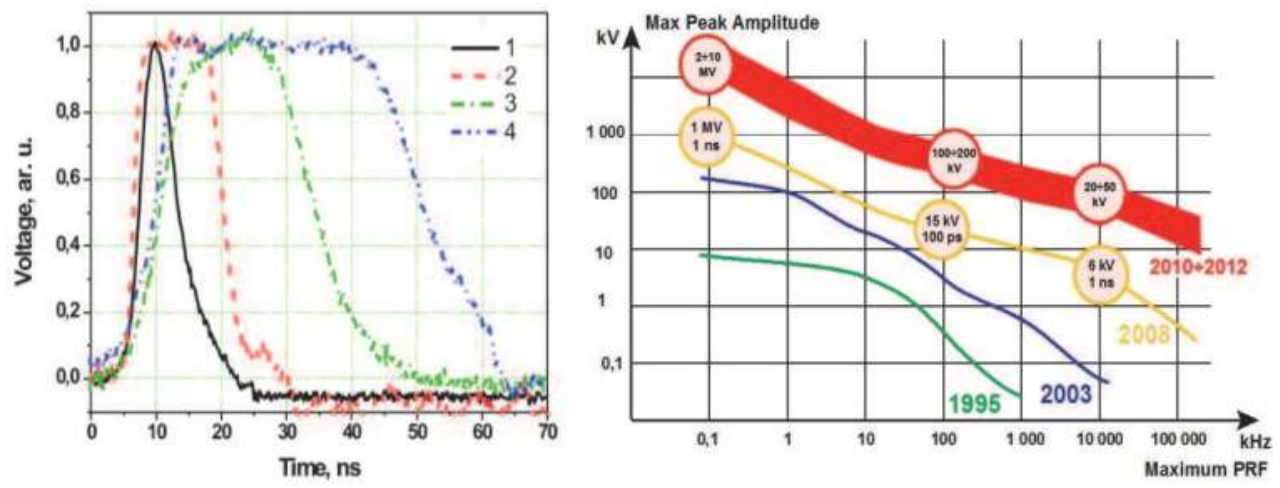

Fig. 19. Progress in ultra-short high-voltage pulse generators. A) typical nanosecond pulse shapes [Roupassov et al, 2008]; b) generators frequency-voltage map [Efanov, 2011].

\subsection{Non-equilibrium plasma recombination and energy relaxation}

For efficient production of large amount of active particles in the gas discharge it is necessary both efficient generation in the gas discharge plasma and slow recombination in collisions with major mixture components.

\subsubsection{Rotational relaxation}

Due to fast rotational-translational (RT) relaxation, rotational degrees of freedom of the molecules are quenched rapidly. This process requires few collisions only. For example, for rotational relaxation in air $\mathrm{O}_{2}(\operatorname{rot})+\mathrm{M} \rightarrow \mathrm{O}_{2}+\mathrm{M}$ and $\mathrm{N}_{2}(\operatorname{rot})+\mathrm{M} \rightarrow \mathrm{N}_{2}+\mathrm{M}$ typical relaxation time is comparable with gas-kinetics time. This means that typical time of rotational states thermalization is $\tau \sim 0.5 \mathrm{~ns}$ under normal conditions. That is why rotationally-excited molecules cannot be considered as active particles for non-thermal acceleration of chemical reactions. Another important point is that the energy of excitation of rotational states is very small (roughly equal to translational temperature) and is significantly lower than typical chemical reaction's thresholds. From the other hand, it is possible to heat the gas through the rotational degrees of freedom excitation. 


\subsubsection{Vibrational relaxation}

Opposite to rotational states relaxation, quenching of vibrationally excites states $\mathrm{N}_{2}$ and $\mathrm{O}_{2}$ (vibrational-translational (VT) relaxation) is very slow process. Time of VT relaxation usually is longer than typical time of plasma-assisted ignition $(\sim 10-100 \mu \mathrm{s})$. These times become comparable when significant amount of $\mathrm{H}_{2}$ or hydrocarbons is presented in te mixture. This means that the vibrationally-excited $\mathrm{N}_{2}$ and $\mathrm{O}_{2}$ molecules can be accumulated in the discharge with intermediate $\mathrm{E} / \mathrm{n}$ values.

VT relaxation leads to slow thermalization of vibrational energy of the molecules. This process becomes faster if the mixtures contain hydrocarbons. For example, VT relaxation of molecular oxygen on methane in stoichiometric methane-air mixture at $\mathrm{T}=1000 \mathrm{~K}$ and pressure $1 \mathrm{~atm}$ has a characteristic time $\mathrm{t} \sim 1.3 \mu \mathrm{s}$. Fast relaxation does not allow to maintain a significant deviation of vibrational temperature from translational on the long time scale. From the other hand, VT relaxation of oxygen in $\mathrm{H}_{2}$-air mixture lasts ten times longer and reaches $\mathrm{t} \sim 15 \mu$ s for $\mathrm{T}=1000 \mathrm{~K}$ and $\mathrm{P}=1 \mathrm{~atm}\left(29 \% \mathrm{H}_{2}\right.$ in the mixture). VT-relaxation of hydrogen in the same mixture takes approximately $380 \mu \mathrm{s}$. Thus, vibrational excitation of hydrogen molecules can be very far from equilibrium during the ignition delay time and can effect significantly the radical's production.

Under uncompleted vibrational relaxation conditions chemical reactions between vibrationally excited molecules play an important role. There are several theoretical models for rate coefficients of reactions between excited reagents. Almost all these models were developed as an engineering substitution of time-consuming ab initio calculations [Kovach et al, 2010; Adamovich et al, 1996; Macheret et al, 1994; Park, 1988]. A model of vibrational energy usage was developed in [Losev et al, 1996]. The model assumes the decrease of the reaction threshold by $\alpha \mathrm{E}_{\mathrm{vib}}$. The efficiency of vibrational excitation $\alpha$ can be estimated using activation energy and thermal effect of the reaction. A model proposed by Macheret [Macheret et al, 1994] allows to estimate the rate constant of simple exchange endothermic reaction. The model requires the fraction of energy release in the reverse reaction directed to vibrational excitation and it is applicable only to a certain type of reactions [Kovach et al, 2010].

It should be noted that almost all analytical models available estimate reaction rate constants using "vibrational temperature". This assumes that we have Boltzmann distribution over vibrational levels. Such an approach cannot be used at non-equilibrium conditions when the population over vibrational levels has non-Boltzann shape [Capitelli, 1996]. State-to-state model was considered in [Starikovskii, 2003]. Reactions between excited hydrogen molecules $\mathrm{H}_{2}(\mathrm{v})$ and radicals are extremely important for ignition and combustion. As an example of reaction rate dependence on the vibrational excitation of reagents let us consider the process

$$
\mathrm{H}_{2}(\mathrm{v})+\mathrm{O} \rightarrow \mathrm{H}+\mathrm{OH}(\mathrm{w})
$$

It is shown in [Light\& Matsumoto, 1978] that ratio of specific constants of the reaction rates at $\mathrm{v}=1$ and $\mathrm{v}=0$ is $\mathrm{k}(\mathrm{v}=1) / \mathrm{k}(\mathrm{v}=0)=2600$ at $\mathrm{T}=300 \mathrm{~K}$. The process at $\mathrm{v}=1$ leads to formation of radical $\mathrm{OH}$ in vibrationaly excited state [Light\& Matsumoto, 1978]

$$
\begin{gathered}
\mathrm{H}_{2}(\mathrm{v}=1)+\mathrm{O}\left({ }^{3} \mathrm{P}\right) \rightarrow \mathrm{H}+\mathrm{OH}(\mathrm{w}=1) \quad\left(k=\left(1.0_{-0.6}^{+0.4}\right) \cdot 10^{-14} \mathrm{~cm}^{3} / \mathrm{s}\right) \\
\mathrm{H}_{2}(\mathrm{v}=1)+\mathrm{O}\left({ }^{3} \mathrm{P}\right) \rightarrow \mathrm{H}+\mathrm{OH}(\mathrm{w}=0) \quad\left(k \leq 4.7 \cdot 10^{-15} \mathrm{~cm}^{3} / \mathrm{s}\right)
\end{gathered}
$$

Experimental measurements show that the averaged factor of vibration energy usage in this reaction is $\alpha=0.31$ [Rusanov\&Fridman, 1985]. Figure 20,a shows results of calculation of the 
reaction rate constant at translation temperature $T_{\text {tr }}=300 \mathrm{~K}$ for various vibration temperatures with the Boltzmann distribution of molecules over vibrational levels. The dependence calculated using model [Starikovskii, 2003] is in good agreement with calculation by $\alpha$-model with experimentally found $\alpha=0.31$ at overheating degree $T_{\text {vib }} / T_{\text {tr }}<$ 5 (Fig. 20,a). Model [Starikovskii, 2003] predicts the ratio $\mathrm{k}(\mathrm{v}=1) / \mathrm{k}(\mathrm{v}=0)=2795$, which is in perfect agreement with experiments [Light\& Matsumoto, 1978] (2600). Ratio of channels to $\mathrm{OH}(\mathrm{w}=1)$ and $\mathrm{OH}(\mathrm{w}=0)$ at $\mathrm{T}=300 \mathrm{~K}$ estimated in [Starikovskii, 2003] is equal to $\mathrm{k}(\mathrm{w}=1) / \mathrm{k}(\mathrm{w}=0)=7.9$, which also is in good agreement with experiments [Light\& Matsumoto, 1978] (>2).

The analysis of the reaction rate constant dependence on the vibrational excitation degree for reaction $\mathrm{OH}+\mathrm{H}_{2}(\mathrm{v}) \rightarrow \mathrm{H}_{2} \mathrm{O}+\mathrm{H}$ is shown on Figure 20,b. The predictions of model [Starikovskii, 2003] are in a good agreement with calculations based on experimentally measured value of $\alpha=0.24$ [Fridman\&Rusanov, 1985]. Work [Light\& Matsumoto, 1978] gives an experimental estimation for ratio of the rate constants of processes $\mathrm{OH}+\mathrm{H}_{2}(\mathrm{v}=0) \rightarrow \mathrm{H}_{2} \mathrm{O}+$ $\mathrm{H}$ and $\mathrm{OH}+\mathrm{H}_{2}(\mathrm{v}=1) \rightarrow \mathrm{H}_{2} \mathrm{O}+\mathrm{H}: \mathrm{k}_{\mathrm{v}=1} / \mathrm{k}_{\mathrm{v}=0} \leq 1000$ at $\mathrm{T}=298 \mathrm{~K}$, which is in good agreement with the estimation by model [Starikovskii, 2003] $\mathrm{k}_{\mathrm{v}=0}=2 \cdot 9 \cdot 10^{-15} \mathrm{~cm}^{-3} \mathrm{~s}^{-1}, \mathrm{k}_{\mathrm{v}=1}=1.8 \cdot 10^{-12} \mathrm{~cm}^{-3} \mathrm{~s}^{-1}$ $\left(\mathrm{k}_{\mathrm{v}=1} / \mathrm{k}_{\mathrm{v}=0}=620\right)$.

Thus, vibrational excitation of reagents can significantly accelerate chemical reactions. The influence of vibrational excitation is limited by VT-relaxation of the molecules. This process becomes extremely fast in the presence of hydrocarbons. In mixtures with hydrogen the efficiency of vibrational excitation increases because of relatively slow vibrational relaxation of $\mathrm{H}_{2}$. Analysis of [Zatsepin et al, 2001] shows the oxidation rate increase in $\mathrm{H}_{2}$-air mixture at $\mathrm{T}=300 \mathrm{~K}$ in $3-5$ times.
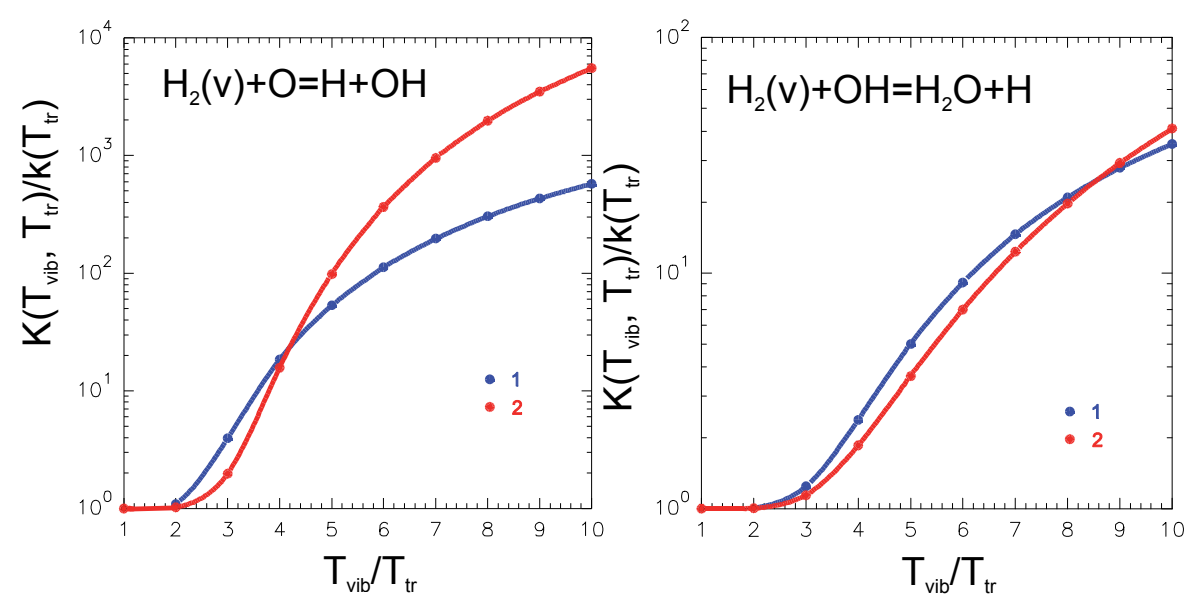

Fig. 20. Dependence of the rate constant of reaction on non-equilibrium excitation degree $\mathrm{T}_{\mathrm{vib} /} \mathrm{T}_{\text {tr }}$ at $\mathrm{T}_{\text {tr }}=300 \mathrm{~K} .1$ - model [Starikovskii, 2003]; $2-\alpha$-model [Macheret et al, 1994].

$$
\text { a) } \left.\mathrm{H}_{2}(\mathrm{v})+\mathrm{O} \rightarrow \mathrm{H}+\mathrm{OH}, \alpha=0.31 ; b\right) \mathrm{H}_{2}(\mathrm{v})+\mathrm{OH} \rightarrow \mathrm{H}_{2} \mathrm{O}+\mathrm{H}, \alpha=0.24 \text {. }
$$

As an example of possible applications of vibrational excitation of the flow we will mention the paper [Bezgin et al, 2006]. Peculiarities of an oblique detonation wave formation in a supersonic hydrogen-oxygen mixture flow over a plane wedge were numerically analyzed. 
Preliminary excitation of molecular vibrations of $\mathrm{H}_{2}$ was shown to lead to a noticeable decrease in the induction zone length and the distance at which the detonation wave was formed. It was demonstrated that the reason for these effects was an intensification of chain reactions in the $\mathrm{H}_{2}-\mathrm{O}_{2}$ (air) mixture owing to the presence of vibrationally excited hydrogen molecules in the flow [Bezgin et al, 2006].

\subsubsection{Electronic levels excitation and relaxation}

At $E / n \sim 100-500 \mathrm{Td}$ the main channel of gas excitation is population of electronic degrees of freedom by electron impact and by energy exchange between vibrationally-excited states. An important exception from this rule is singlet state of molecular oxygen $\mathrm{O}_{2}(\mathrm{a})$. This state has a low excitation threshold and the maximum efficiency of its population corresponds to $E / n \sim 3-10 \mathrm{Td}$.

There are number of different electronically-excited particles in low-temperature plasma. Unfortunately, reaction rate constants, quenching rates and products are known only for limited number of them. That is why we will mention here the most important levels from the point of view of plasma assisted combustion only.

The efficiency of energy of electronic state usage for plasmachemistry depends on the ratio between channels of depopulation of the state. For example, if the radiative life-time of the state is too short we will have some photon flux but no reactions with this state. Collisional quenching efficiency depends on the products of the reaction. Quenching of triplet states of nitrogen molecules by molecular oxygen lead to oxygen dissociation and atomic oxygen production. Another example - quenching of singlet oxygen molecules by hydrogen or hydrocarbons mostly leads to heat release without formation of active radicals.

The most important reactions with electronically-excited molecules from the point of view of plasma assisted combustion are channels which lead to radicals formation. There are four different ways to produce radicals through excitation of electronically-excited states:

1. Excitation of the molecular electronic state and radicals production in chemical chains:
a. $\mathrm{O}_{2}+\mathrm{e} \rightarrow \mathrm{O}_{2}\left(\mathrm{a}^{1} \Delta_{\mathrm{g}}\right)[0.98 \mathrm{eV}]+\mathrm{H} \rightarrow \mathrm{O}\left({ }^{3} \mathrm{P}\right)+\mathrm{OH}$
b. $\mathrm{O}_{2}+\mathrm{e} \rightarrow \mathrm{O}_{2}\left(\mathrm{~b}^{1} \Sigma_{\mathrm{g}}{ }^{+}\right)[1.64 \mathrm{eV}]+\mathrm{H}_{2} \rightarrow \mathrm{OH}+\mathrm{OH}$
c. $\mathrm{N}_{2}+\mathrm{e} \rightarrow \mathrm{N}_{2}\left(\mathrm{~A}^{3} \Sigma_{\mathrm{u}}+\right)[6.2 \mathrm{eV}]+\mathrm{O}_{2} \rightarrow \mathrm{N}_{2} \mathrm{O}+\mathrm{O}\left({ }^{3} \mathrm{P}\right)$

2. Excitation of the molecule to repulsive or pre-dissociative term leads to molecule dissociation and formation of two radicals:
a. $\mathrm{O}_{2}+\mathrm{e} \rightarrow \mathrm{O}_{2}\left(\mathrm{~B}^{3} \Sigma_{u}^{-}\right)[8.4 \mathrm{eV}] \rightarrow \mathrm{O}\left({ }^{3} \mathrm{P}\right)+\mathrm{O}\left({ }^{1} \mathrm{D}\right)+\mathrm{e}$
b. $\quad \mathrm{O}_{2}+\mathrm{e} \rightarrow \mathrm{O}_{2}\left(\mathrm{C}^{3} \Delta_{\mathrm{u}}\right)[6.87 \mathrm{eV}] \rightarrow \mathrm{O}\left({ }^{3} \mathrm{P}\right)+\mathrm{O}\left({ }^{3} \mathrm{P}\right)+\mathrm{e}$
c. $\mathrm{H}_{2}+\mathrm{e} \rightarrow \mathrm{H}_{2}\left(\mathrm{a}^{3} \Sigma_{\mathrm{g}}{ }^{+}\right)[11.8 \mathrm{eV}] \rightarrow \mathrm{H}\left({ }^{1} \mathrm{~S}\right)+\mathrm{H}\left({ }^{1} \mathrm{~S}\right)+\mathrm{e}$

3. Excitation of the molecule and dissociative quenching of excited state by another molecule:
a. $\mathrm{N}_{2}+\mathrm{e} \rightarrow \mathrm{N}_{2}\left(\mathrm{C}^{3} \Pi_{\mathrm{u}}\right)[11.02 \mathrm{eV}]+\mathrm{O}_{2} \rightarrow \mathrm{N}_{2}+\mathrm{O}\left({ }^{3 P}\right)+\mathrm{O}\left({ }^{1} \mathrm{D}\right)$
b. $\mathrm{N}_{2}+\mathrm{e} \rightarrow \mathrm{N}_{2}\left(\mathrm{C}^{3} \Pi_{\mathrm{u}}\right)[11.02 \mathrm{eV}]+\mathrm{H}_{2} \rightarrow \mathrm{N}_{2}+\mathrm{H}\left({ }^{1} \mathrm{~S}\right)+\mathrm{H}\left({ }^{1} \mathrm{~S}\right)$
c. $\mathrm{O}_{2}+\mathrm{e} \rightarrow \mathrm{O}_{2}\left(\mathrm{~A}^{3} \Sigma_{\mathrm{g}}{ }^{+}\right)[4.5 \mathrm{eV}]+\mathrm{CH}_{4} \rightarrow \mathrm{O}_{2}+\mathrm{CH}_{3}+\mathrm{H}\left({ }^{1} \mathrm{~S}\right)$

4. Excitation of the molecular electronic state with radiative depopulation, high-energy photon flux generation and dissociation (ionization) of gas molecules by this radiation:
a. $\quad \mathrm{N}_{2}+\mathrm{e} \rightarrow \mathrm{N}_{2}\left(\mathrm{~B}^{1} \Pi_{\mathrm{u}}\right)[12.5 \mathrm{eV}] \rightarrow \mathrm{N}_{2}+\mathrm{h} v \rightarrow \mathrm{O}_{2}+\mathrm{h} v \rightarrow \mathrm{O}_{2}{ }^{+}+\mathrm{e}$
b. $\quad \mathrm{N}_{2}+\mathrm{e} \rightarrow \mathrm{N}_{2}\left(\mathrm{~B}^{1} \Pi_{\mathrm{u}}\right)[12.5 \mathrm{eV}] \rightarrow \mathrm{N}_{2}+\mathrm{h} v \rightarrow \mathrm{CH}_{4}+\mathrm{h} v \rightarrow \mathrm{CH}_{3}+\mathrm{H}$
c. $\mathrm{H}_{2}+\mathrm{e} \rightarrow \mathrm{H}_{2}\left(\mathrm{a}^{3} \Sigma_{\mathrm{g}}+\right)[11.8 \mathrm{eV}] \rightarrow \mathrm{H}_{2}\left(\mathrm{~b}^{3} \Sigma_{\mathrm{g}}\right)+\mathrm{h} v \rightarrow \mathrm{O}_{2}+\mathrm{h} v \rightarrow \mathrm{O}+\mathrm{O}$ 
Comprehensive detailed kinetic models were discussed, for example, in [Kossyi et al, 1992] for $\mathrm{N}_{2}-\mathrm{O}_{2}$ mixtures, in [Zatsepin et al, 2001] for $\mathrm{H}_{2}-\mathrm{O}_{2}-\mathrm{N}_{2}$ mixtures and in [Anikin et al, 2006] for $\mathrm{C}_{\mathrm{x}} \mathrm{H}_{\mathrm{y}}-\mathrm{O}_{2}$ mixtures. It should be noted however, that channel branching, rate coefficients and even products of such reactions are not very well known. The first group of processes was investigated much better, than second and third. Simultaneous presence in the plasma of all sorts of excited particles and radicals makes detailed kinetic analysis an extremely challenging and resource-consuming task. As an example we just mention that mixture composition variation, very popular approach in combustion chemistry, will not work in plasma chemistry because simultaneously with afterglow kinetics variation we will change electron energy distribution function in the discharge phase and kinetics of gas excitation. Mechanism (I) requires very low electric field to increase the efficiency of the excitation process because of low energy threshold for oxygen singlet states population. On the contrary, mechanisms (II)-(IV) require high $E / n$ value and high electron energy for upper electronic states excitation.

\subsection{Low-energy electronic states excitation}

Singled oxygen molecules as a tool for ignition and combustion control were proposed by group of Starik [Smirnov et al, 2008]. The effect of the excitation of oxygen molecules to the $\mathrm{O}_{2}\left(a^{1} \Delta_{\mathrm{g}}\right)$ and $\mathrm{O}_{2}\left(b^{1} \Sigma_{\mathrm{g}}{ }^{+}\right)$electronic states in the electrical discharge on the velocity of laminar flame propagation in the $\mathrm{H}_{2}-\mathrm{O}_{2}$ mixture was analyzed. The calculations showed that the excitation of $\mathrm{O}_{2}$ molecules to the $a^{1} \Delta_{g}$ and $b^{1} \Sigma_{\mathrm{g}}{ }^{+}$electronic states allows one to increase significantly (by a factor of 2.5) the velocity of flame propagation for the fuel lean hydrogenoxygen mixture. For stoichiometric and fuel rich mixtures the increase in flame velocity due to an abundance of singlet oxygen molecules in the mixture was found to be significantly smaller (about a factor of 1.1). Later the same team proposed to use a laser radiation at $\lambda=$ $762.346 \mathrm{~nm}$ for $\mathrm{O}_{2}$ molecules excitation to the $b^{1} \Sigma_{\mathrm{g}}{ }^{+}$electronic state. Experimental observation of the shortening of the induction zone length in a premixed mode of combustion in a subsonic $\mathrm{H}_{2}-\mathrm{O}_{2}$ low pressure flow due to the presence of oxygen molecules excited to the singlet $a^{1} \Delta_{g}$ electronic state was reported in [Smirnov et al, 2008]. The low pressure electric glow discharge was used to produce singlet oxygen molecules. The analysis showed that $\sim 1 \%$ of $\mathrm{O}_{2}\left(a^{1} \Delta_{g}\right)$ molecules in the $\mathrm{H}_{2}-\mathrm{O}_{2}$ mixture allows to noticeably reduce the ignition delay length and to ignite the mixture at a lower temperature. Authors conclude that the results obtained demonstrate the possibility to intensify the combustion of a hydrogenoxygen mixture by means of excitation of $\mathrm{O}_{2}$ molecules by electrical discharge at low pressure $(P=10-20$ Torr $)$.

A numerical study of the plasma assisted ignition of hydrogen-oxygen mixtures at different $E / n$ has been performed in [Wu et al, 2010]. Results at low $E / n$ values are compared with experimental data [Smirnov et al, 2008] and good agreement between experimental and numerical data was demonstrated. It was shown that the efficiency of radicals production through the oxygen singlet states excitation is limited by collisional quenching of SDO molecules in oxygen-fuel mixtures; in oxygen-nitrogen mixtures main efficiency limitation comes from discharge energy flux alternation by vibrational excitation of nitrogen [Wu et al, 2010] (see also Figure 17,b). In paper [Wu et al, 2010] two different mechanisms of radical formation were analyzed: 1 ) at low $E / n$ - through oxygen singlet states excitation with subsequent quenching and conversion into radicals in reactions with fuel molecules, and 2 ) at high $E / n$ - through direct dissociation of molecular oxygen by electron impact and 
quenching of nitrogen triplet states in collisions with molecular oxygen. It was shown that the first channel is more efficient in pure oxygen, while the second is much more efficient for mixtures containing more than $10 \%$ of nitrogen.

\subsection{High electronic states excitation}

In papers [Kof\&Starikovskii, 1996-1, 1996-2] authors proposed to use pulsed nanosecond discharges for plasma assisted ignition and flame stabilization. The idea was to maintain an extremely high electrical field for a short period of time. This approach allows to generate highly-excited nonequilibrium plasma with the energy distribution shifted to the electronic excitation and dissociation. Short pulse duration restricts the plasma conductivity increase and keeps the energy density in the gas on the relatively low level (equivalent gas heating is in the range of 10-100 K). Paper [Starikovskiy et al, 2011] summarizes the requirements to the pulse discharges to maintain the high efficiency of excitation:

1. High-voltage pulse amplitude is limited to set the value of the reduced electric field $E / n$ $>$ 200-300 Td in the discharge gap which provides optimal conditions for dissociation of molecular oxygen by electron impact and quenching of nitrogen excited states (in air and lean fuel-air mixtures).

2. High-voltage rise $d U / d t>300 \div 1000 \mathrm{kV} /(\mathrm{ns} \times$ atm) to obtain the field intensity sufficient for homogeneous ionization wave formation. This condition allows to achieve the homogeneous gas excitation in the gap and simplifies the analysis of the kinetic data. It shold be mentioned, however, that for practical applications inhomogeneous excitation may have specific advantages in some cases (for example, reduction of energy consumption).

This type of the discharge was used in [Zatsepin et al, 2001] to investigate low-temperature kinetics in plasma of pulsed nanosecond discharge. Oxidation of molecular hydrogen in stoichiometric hydrogen-air mixture in the Fast Ionization Wave (FIW) was studied at total pressures $\mathrm{p}=1-8$ Torr, and the detailed kinetics of the process has been numerically investigated. The excitation of the gas in FIW and dynamics of molecular hydrogen concentration were monitored with the use of measurements of absolute $\mathrm{H}_{2}$ radiation intensity (transition $\mathrm{a}^{3} \Sigma_{\mathrm{g}}{ }^{+} \rightarrow \mathrm{b}^{3} \Sigma_{\mathrm{u}}{ }^{+}$). Comparison of calculation and experimental results allows to make a conclusion that the gas is predominantly excited behind the FIW front in relatively low electric fields $E / n \sim 300-600 \mathrm{Td}$ at electron concentration $\mathrm{n}_{\mathrm{e}} \sim(1-2) \times 10^{12} \mathrm{~cm}^{-3}$ during approximately $10 \mathrm{~ns}$ and the excitation can be described with a good accuracy using the two-term approximation of Boltzmann's equation. In the subsequent processes the reactions including electron-excited particles play a dominant role for the time up to $100 \mathrm{~ns}$, ion-molecular reactions - for the time of microsecond range, reactions including radicals mostly contribute for the time interval of several milliseconds. The most critical processes have been separated for each time interval. The principal role of processes with formation of excited components that support the development of the chain mechanism of oxidation has been shown.

Detailed state-to-state kinetic mechanism [Zatsepin et al, 2001] includes 750 chemical and 8700 vibrational exchange processes with participation of 254 particles including electronexcited and charged atoms and molecules, electrons, radicals, non-excited components, and vibrational-excited molecules $\mathrm{H}_{2}, \mathrm{O}_{2}, \mathrm{~N}_{2}, \mathrm{H}_{2} \mathrm{O}$ and $\mathrm{OH}$-radical. The most important processes in each time interval in plasma afterglow and radicals recombination were identified. Because the overall picture observed in [Zatsepin et al, 2001] is very typical for plasma assisted ignition by pulsed discharges, we will analyze it in more details. 


\subsection{Kinetics of plasma assisted combustion below self-ignition threshold}

The mixture compression in the engine before the ignition leads to temperature increase. For example, in IC engines initial temperature is close to $600 \mathrm{~K}$, in GTEs - 600-700 K, in SCRAMjets $650-800 \mathrm{~K}$. In these cases the initial temperature of the mixture is below or close to self-ignition threshold. That is why this range of parameters attracts in attention of researchers. From the other hand, this temperature interval is poor investigated from the point of view of chemical kinetic mechanisms. The problem is the lack of data for lowtemperature mechanisms validation. As an example, methane combustion GRIMech-3.0 model was validated in the range $1250-2500 \mathrm{~K}$. C1-C4 Konnov's mechanism was validated down to $\sim 910 \mathrm{~K}$, hydrogen Popov's mechanism [Popov, 2008] - to $880 \mathrm{~K}$. Direct extrapolation of these models down to room temperature conditions or even to intermediate temperature range below self-ignition threshold, of course, is very questionable (see, for example, analysis in [Uddi et al, 2011]). Thus the task of kinetics investigations in low temperature region becomes extremely difficult and complex. We have to take into account kinetics in gas discharge and plasma afterglow and almost unknown mechanisms of chemical chains initiation under low temperature conditions.

Another problem of investigations of kinetics in plasma is gas discharge inhomogeneity. Under low pressure conditions homogeneous gas ionization and excitation can be achieved even with rather slow voltage increase across the discharge gap. Pressure increase requires a sharp decrease of the voltage rise time (relations 1)-2) above suggest to keep the voltage rise rate on the level of $\sim 1 \mathrm{MV} / \mathrm{ns} / \mathrm{atm}$ for room temperature air to achieve homogeneous excitation). For low pressure conditions this leads to critical voltage rise time about $8 \mathrm{~ns}$ and correlate with homogeneous picture of plasma formation in the reaction chamber of $5 \mathrm{~cm}$ diameter.

Uncontrollable inhomogeneous excitation significantly compromises the kinetic analysis. That is why some authors prefer to use controlled inhomogeneous excitation instead. For example, in papers [Bak et al, 2011; Stancu et al, 2010; Grisch et al, 2009; Wu et al, 2010, 2011] the point-to-point electrodes geometry was used. This geometry generates non-uniform streamer-like discharge but because of its high reproducibility allows to reconstruct the spatial distribution of excitation and kinetics in plasma.

In [Grisch et al, 2009], detailed experimental investigation of a non-equilibrium nanosecond pulsed discharge in premixed $\mathrm{CH}_{4} /$ air mixtures at atmospheric pressure has been carried out. The electron temperature and density properties were measured using laser Thomson scattering (LTS). Temperature measurements were performed using $\mathrm{N}_{2}$ CARS thermometry to quantify the energy transfer in the gas mixture. Effect of the discharge on the local temperature shows the existence of the ignition of the gas mixture for equivalence ratio between 0.7 and 1.3. The experiments demonstrated significant reductions in ignition delay and increased lean burn capability relative to conventional spark ignition. Fast development of a flame kernel is then observed. $\mathrm{OH}$ and $\mathrm{CH}$ PLIF experiments were performed to confirm the large $\mathrm{OH}$ and $\mathrm{CH}$ streamer-induced production over the discharge volume.

Papers [Bak et al, 2011; Stancu et al, 2010] discuss an important question on the channels of molecular oxygen dissociation in pulsed discharges. In [Bak et al, 2011] time-resolved emission measurements for $\mathrm{N}_{2}(\mathrm{C}-\mathrm{B})$ and $\mathrm{N}_{2}(\mathrm{~B}-\mathrm{A})$ transitions were carried out in nanosecond pulsed discharges in air and pure nitrogen. 0-D kinetic simulations coupled with energy equation are conducted to predict quenching rate coefficients of quenching of $\mathrm{N}_{2}{ }^{*}$ by $\mathrm{N}_{2}$ and dissociative quenching of $\mathrm{N}_{2}{ }^{*}$ by $\mathrm{O}_{2}$ by matching the simulated emission curves to the 
corresponding measurements. The dissociative quenching was found to be responsible for $82 \%$ of O production whereas the electron-impact dissociation was $\sim 5 \%$.

Papers [Pai et al, 2009, Stancu et al, 2010] reports the results of investigations of nanosecond repetitively pulsed discharge in atmospheric pressure discharge in air or nitrogen preheated at $1000 \mathrm{~K}$. The ground state of atomic oxygen was measured by two-photon absorption laser induced fluorescence, the density of $\mathrm{N}_{2}(\mathrm{~A})$ was measured by cavity ring down spectroscopy and the densities of $\mathrm{N}_{2}(\mathrm{~B})$ and $\mathrm{N}_{2}(\mathrm{C})$ were measured by optical emission spectroscopy. Measurements of $\mathrm{O}, \mathrm{N}_{2}(\mathrm{~B})$ and $\mathrm{N}_{2}(\mathrm{C})$ densities have confirmed that the formation of atomic oxygen occurs through the fast two-step mechanism through excitation and quenching of nitrogen triplet states [Stancu et al, 2009].

Papers [Wu et al, 2010, 2011] present measurements of time evolution of hydroxyl radicals in premixed hydrocarbon-air flow in the afterglow of a nanosecond pulsed discharge at atmospheric pressure. The temperature ranged from 300 to $800 \mathrm{~K}$. The fuels were methane, ethane, propane and butane, at an equivalence ratio of 0.1 . The plasma was generated by 20 $\mathrm{kV}$ pulses of $10 \mathrm{~ns}$ duration with $<1 \mathrm{~ns}$ rise time at repetition rate of $10 \mathrm{~Hz}$. The tip electrode shape ensured a stable streamer discharge. The reactant flow rate was set at $\sim 20 \mathrm{~cm} / \mathrm{s}$ so that each discharge pulse occurred in a fresh gas mixture. Laser induced fluorescence was used to measure the concentration of $\mathrm{OH}$ radicals after the discharge. The energy of the excitation laser was adjusted to insure that the measurements were made under saturation conditions for all experiments. The time evolution of $\mathrm{OH}$ radicals was tracked by adjusting the delay time between the high-voltage pulse and the concentration measurement. It was shown that the $\mathrm{OH}$ concentration demonstrates three maxima: immediately after discharge, on time scale $\sim 100 \mu \mathrm{s}$, and the third $\sim 2-5 \mathrm{~ms}$ after the initiation. This behavior demonstrates relatively long chains development under low temperature conditions below self-ignition threshold.

The important conclusion was made in [Uddi et al, 2011; Wu et al, 2010; Wu et al, 2011] that a new, validated mechanism for low temperature hydrocarbon combustion is required for qualitative description of plasma assisted combustion below self-ignition threshold. This problem is still unsolved at require a lot of new efforts.

\section{Plasma assisted combustion above self-ignition threshold}

Kinetics above self-ignition threshold is relatively good understood for hydrogen and small hydrocarbons. Verified kinetic models exist for all saturated hydrocarbons from methane to n-decane at temperatures $\mathrm{T}>1000-1200 \mathrm{~K}$ and pressures from several Torr to several atmospheres. Presence of detailed chemical models simplifies the analysis of plasma assisted combustion experiments in this range of parameters. The only difference between auto-ignition and plasma assisted ignition is a high concentration of radicals from the very beginning of the process and potential influence of non-equilibrium mechanisms with participation of vibrationally- and electronically- excited particles and ions.

The challenge of high-temperature experiments is the controllable heating of the mixture in combination with the homogeneous non-equilibrium excitation by gas discharge. The problem was solved in [Kof\&Starikovskiy, 1996-1; 1996-2] where the combined excitation of the combustible mixture by shock wave and fast ionization wave was proposed. Experimental installation was based on the shock tube coupled with the discharge section. Discharge was generated by Marks-type high-voltage pulse generator. The generator consisted of 10 steps and operated at $\mathrm{U}=80-250 \mathrm{kV}$. Ferrite line with non-linear response 
and an impedance of $40 \mathrm{Ohm}$ allowed to decrease the pulse leading front down to $500 \mathrm{ps}$. The voltage increase rate on a high voltage electrode was up to $500 \mathrm{kV} / \mathrm{ns}$ and allowed a fast ionization wave formation in the discharge section.

Ignition delay time was analyzed for oxygen-hydrogen mixtures and numerical analysis of chemical kinetics was performed for simultaneous mixture excitation by shock wave and high voltage ionization wave. Ionization wave influence ( $\mathrm{U} \sim 250 \mathrm{kV}, \mathrm{t}_{\text {pulse }} \sim 40 \mathrm{~ns}$ ) on the ignition delay time of the mixture $\mathrm{H}_{2}: \mathrm{O}_{2}: \mathrm{N}_{2}=5: 19: 76$ at $\mathrm{p}=1 \mathrm{~atm}$ was investigated. High efficiency of the fast ionization wave for spatially-uniform excitation of the chemicallyreacting systems has been found [Kof\&Starikovskiy, 1996-1; 1996-2]. The experimental works using this installation show the high efficiency of this methodology for hightemperature plasma assisted combustion investigation (see, for example, [Aleksandrov et al, 2009-1; 2009-2; Kosarev et al, 2009; 2008; 2008-2; Starikovskii et al, 2006; Starikovskii, 2005; Starikovskaia et al, 2004; Bozhenkov et al, 2003; 2002]).

The kinetics of ignition in $\mathrm{C}_{n} \mathrm{H}_{2 n}+2 \mathrm{O}_{2}$ : $\mathrm{Ar}$ mixtures for $n=2$ to 5 has been studied experimentally and numerically after a high-voltage nanosecond discharge [Kosarev et al, 2008]. The ignition delay time behind a reflected shock wave was measured with and without the discharge. It was shown that the initiation of the discharge with a specific deposited energy of $10-30 \mathrm{~mJ} / \mathrm{cm}^{3}$ leads to an order of magnitude decrease in the ignition delay time. Discharge processes and following chain chemical reactions with energy release were simulated. The generation of atoms, radicals and excited and charged particles was numerically simulated using the measured time-resolved discharge current and electric field in the discharge phase. The calculated densities of the active particles were used as input data to simulate plasma-assisted ignition. The sensitivity of the results to variation in electron cross sections, reaction rates and radical composition was investigated. Good agreement was obtained between the calculated ignition delay times and the experimental data. The analysis of the simulation results showed that the effect of nonequilibrium plasma on the ignition delay is associated with faster development of chain reactions, due to atoms and radicals produced by the electron impact dissociation of molecules in the discharge phase. Finally, we studied the role of various hydrocarbon radicals in the plasma-assisted ignition of the mixtures under consideration.

Figures 21,a-d show the delay times measured and calculated in [Kosarev et al, 2008] in $\mathrm{C}_{2} \mathrm{H}_{6}$ - to $\mathrm{C}_{5} \mathrm{H}_{12}$-containing stoichiometric mixtures with oxygen with $90 \%$ Ar dilution as a function of the gas temperature for autoignition and plasma-assisted ignition. The effect of gas discharge leads to a drastic decrease in the ignition delay and to ignition of the mixtures at noticeably lower temperatures and gas number densities.

Good agreement between the measured and calculated ignition delay time after the discharge in most cases studied shows that the developed kinetic model adequately describes PAI under the conditions considered. Simulation of discharge processes was also validated by comparison between calculated and measured temporal evolution in the discharge current and in the specific energy deposited in the discharge phase.

It should be mentioned that kinetic model of active particles formation in the discharge used in [Kosarev et al, 2009; Aleksandrov et al, 2009] is significantly simplified and rate coefficients of number of processes are not very well known. It is related to ions composition and in part to composition of hydrocarbon radicals. Fortunately under conditions of typical lean mixtures combustion the atomic oxygen always plays a major role. Atomic hydrogen and hydrocarbon radicals are less important but processes of their formation are also well investigated and could be modeled with rather high accuracy. Uncertainty in the radical's 
relative composition is not of critical importance under such conditions because the ignition delay time and rate of chemical energy release at high temperatures does not significantly depend on the radical's nature [Aleksandrov et al, 2009]. Thus even the plasma-chemical systems are very complex and some processes are not investigated in details at the moment, plasma assisted ignition and combustion at high temperatures are controlled by rather simple and well-understood mechanisms and radicals.
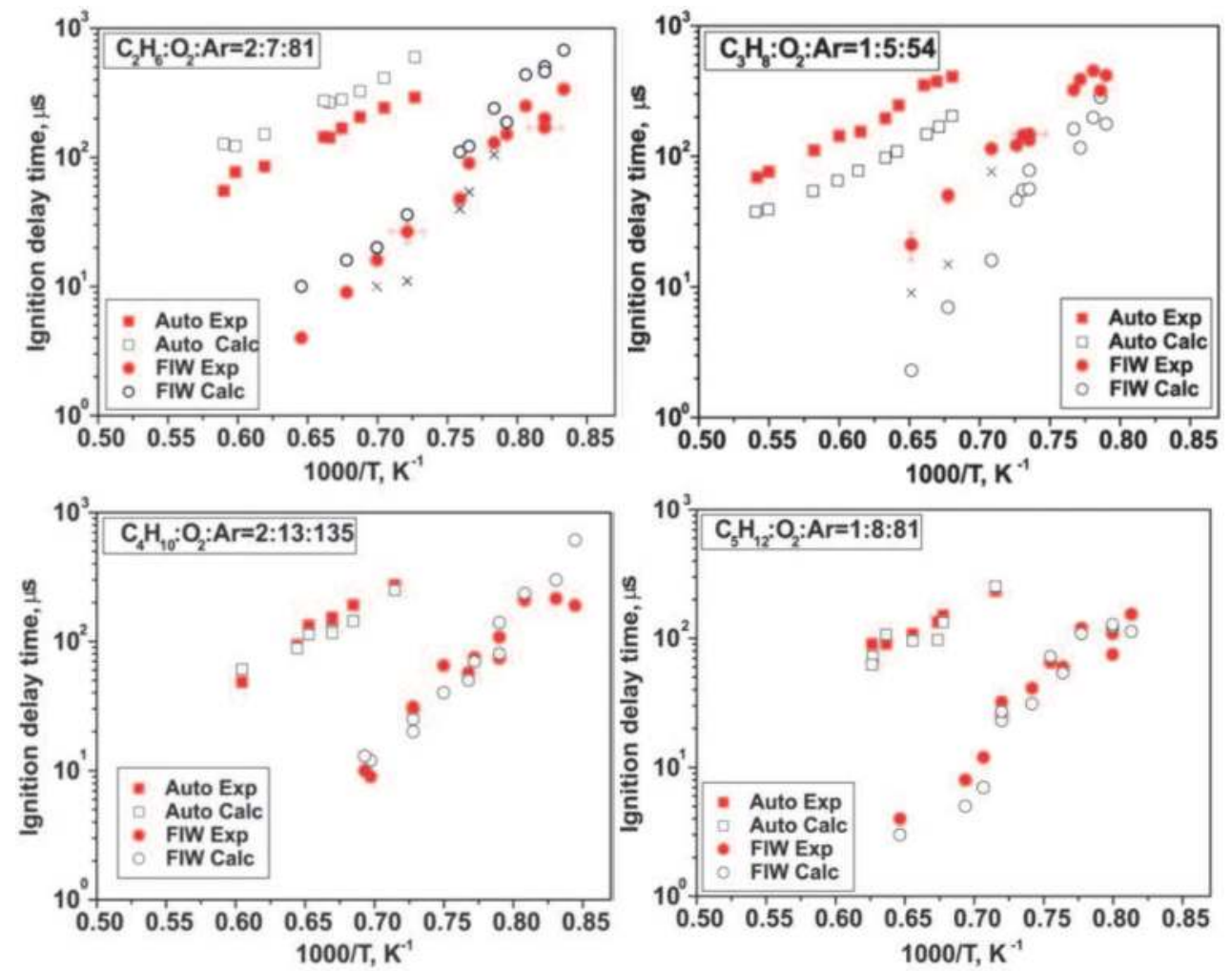

Fig. 21. The delay time for autoignition and ignition with the discharge as a function of temperature. Closed symbols correspond to measurements and open symbols correspond to calculations. a) $\mathrm{C}_{2} \mathrm{H}_{6}: \mathrm{O}_{2}:$ Ar mixture; b) $\mathrm{C}_{3} \mathrm{H}_{8}: \mathrm{O}_{2}$ :Ar mixture; c) $\mathrm{C}_{4} \mathrm{H}_{10}: \mathrm{O}_{2}:$ Ar mixture;

d) $\mathrm{C}_{5} \mathrm{H}_{12}: \mathrm{O}_{2}$ :Ar mixture [Kosarev et al, 2008].

\subsection{Vacuum Ultraviolet Emission of the discharge}

It is well known that both equilibrium and non-equilibrium plasma are strong sources of vacuum ultraviolet radiation (VUV). Absorption of VUV radiation by oxygen leads to molecular oxygen dissociation with quantum efficiency close to one. Thus ultraviolet sources potentially can generate high concentration of active radicals in the gas.

In [Berezhetskaya et al, 2005] the possibility to utilize the discharge VUV self-emission for ignition stimulation has been considered. The pulsed microwave radiation was generated by 
a MI-389 magnetron. The radiation parameters are the following: peak power $P_{i} \leq 400 \mathrm{~kW}$, pulse duration $\tau_{\mathrm{f}} \leq 50 \mathrm{~ms}$, wavelength $\lambda_{\mathrm{f}} \sim 2.5 \mathrm{~cm}$, repetition frequency $\mathrm{f} \sim 10 \mathrm{~Hz}$. It was shown that, both in hydrogen-oxygen and in methane-oxygen media, the non-selfsustained discharge initiates the primary combustion wave with relatively low temperature and low glow intensity. In contradiction to the literature data, the experiments did not show a significant difference between the propagation velocities of combustion waves in hydrogen- and methane-containing media, and considerable (above $1000 \mathrm{~K}$ ) temperature jumps were observed behind the front of the primary wave. After the primary wave started from the initiator passed some distance, a bright burst occurred rapidly and almost simultaneously throughout the region under observation. This burst is characteristic of the transition to the explosive combustion of a gas mixture. The observed specifics of the initiation and propagation of the combustion is attributable to both "gasdynamic" and "kinetic" mechanisms (in particular, to the action of ultraviolet radiation on the gas medium; the source of radiation is numerous sparks arising at metal-dielectric contacts at the target surface irradiated with the microwave beam).

It should be mentioned that excitation of upper states with typical thresholds of $10-15 \mathrm{eV}$ require significant energy. Energy price per radical in this case becomes comparable or even higher than for ionization channel. That is why the VUV radiation cannot be considered as a primary channel of mixture excitation. From the other side radiation can propagate through the gas and de-localize the discharge's excitation.

\subsection{Role of gas ionization and plasma recombination in PAC}

Ionization is very expensive process from the point of view of energy consumption. Best results can be achieved using e-beam with the energy above $1 \mathrm{keV} \mathrm{(} 34 \mathrm{eV} /$ ion in air). Gas discharges at extremely high overvoltage operate in the same mode, generating flux of runaway electrons with the energy close to voltage applied [Vasilyak et al, 1994]. Gas discharge in the form of fast ionization wave, developing at $E / n \sim 1000 \mathrm{Td}$, has approximately two times lower efficiency of electron-ion pair's production $(\sim 65 \mathrm{eV} /$ ion). Gas discharges with lower overvoltage $(E / n \sim 100 \mathrm{Td}$ for streamers, glow discharges) have very low efficiency of gas ionization.

Another important point about gas ionization is fast plasma recombination. This process is discussed in details in [Aleksandrov et al, 2009; 2010]. Even for electron's concentration $n_{e} \sim$ $10^{12} \mathrm{~cm}^{-3}$ recombination time at $\mathrm{T} \sim 300 \mathrm{~K}$ is less than $1 \mu$ s because of cluster ions formation, and for $\mathrm{T} \sim 3000 \mathrm{~K}$ is order of magnitude longer $(\sim 10 \mu \mathrm{s}$, molecular ion - electron recombination mechanism). Fast termalization of ionization energy leads to effective gas heating in microsecond time scale [Aleksandrov et al, 2009]. Combination of these two factors - very high energy price of ionization and very high rate of recombination - makes the ionization ineffective from the point of view of plasma assisted combustion. Authors of [Anikin et al, 2001; Starikovskiy, 2003] showed that the efficiency of radicals production in air-fuel mixtures has a maximum at $E / n \sim 200-400 \mathrm{Td}$. Further increase of electrical field value leads to shift of discharge energy distribution to gas ionization and increases the price of radical's production.

Of course detailed analysis of the efficiency of gas ionization on the ignition process should take into account the gas composition, temperature, pressure and plasma density. For example for high concentration of electrons the main process of plasma recombination is electron-ion dissociative recombination [Aleksandrov et al, 2009]: 


$$
\begin{aligned}
& \mathrm{N}_{2}++\mathrm{e} \rightarrow \mathrm{N}\left({ }^{4} \mathrm{~S}\right)+\mathrm{N}\left({ }^{4} \mathrm{~S},{ }^{2} \mathrm{D}\right) \\
& \mathrm{O}_{2}{ }^{+}+\mathrm{e} \rightarrow \mathrm{O}\left({ }^{3} \mathrm{P}\right)+\mathrm{O}\left({ }^{3} \mathrm{P},{ }^{1} \mathrm{D}\right)
\end{aligned}
$$

For intermediate concentration of electrons (less than $10^{12} \mathrm{~cm}^{-3}$ ) binary recombination becomes slower than charge transfer reactions and reactions of cluster ions formation:

$$
\begin{gathered}
\mathrm{N}_{2}^{+}+\mathrm{N}_{2}+\mathrm{M} \rightarrow \mathrm{N}_{4}^{+}+\mathrm{M} \\
\mathrm{N}_{4}^{+}+\mathrm{O}_{2} \rightarrow \mathrm{O}_{2}{ }^{+}+\mathrm{N}_{2}+\mathrm{N}_{2} \\
\mathrm{O}_{2}{ }^{+}+\mathrm{O}_{2}+\mathrm{M} \rightarrow \mathrm{O}_{4}^{+}+\mathrm{M}
\end{gathered}
$$

Recombination of cluster ions $\mathrm{O}_{4}{ }^{+}$and $\mathrm{N}_{4}{ }^{+}$is order of magnitude faster process than recombination of molecular ions and at low temperatures $(\sim 300 \mathrm{~K})$ and electron

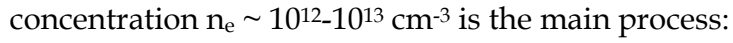

$$
\begin{gathered}
\mathrm{N}_{4}^{+}+\mathrm{e} \rightarrow \mathrm{N}_{2}+\mathrm{N}_{2} \\
\mathrm{O}_{4}^{+}+\mathrm{e} \rightarrow \mathrm{O}_{2}+\mathrm{O}_{2} \\
\mathrm{O}_{4}^{+}+\mathrm{e} \rightarrow \mathrm{O}_{2}+\mathrm{O}+\mathrm{O}
\end{gathered}
$$

Products of recombination of cluster ions are not very well known. Recent measurements of ozone formation in pulsed SDBD demonstrate very low oxygen dissociation degree in the discharge at high $E / n(\sim 1000 \mathrm{Td})$ and high pressure $(\mathrm{P}=1 \mathrm{~atm})$. It demonstrates that the channel $\mathrm{O}_{4}{ }^{+}+\mathrm{e}=\mathrm{O}_{2}+\mathrm{O}_{2}$ prevails and suppresses the atomic oxygen formation in plasma afterglow, increasing simultaneously the energy release to translational degrees of freedom. At low plasma density $\left(\mathrm{n}_{\mathrm{e}} \sim 10^{10} \mathrm{~cm}^{-3}\right)$ and high oxygen concentration the main channel of electron losses is an attachment [Aleksandrov et al, 2009]:

$$
\mathrm{O}_{2}+\mathrm{e}+\mathrm{M} \rightarrow \mathrm{O}_{2}^{-}+\mathrm{M}
$$

Ion-ion recombination becomes the most important process:

$$
\begin{gathered}
\mathrm{O}_{2}^{-}+\mathrm{O}_{2}^{+}+\mathrm{M} \rightarrow \mathrm{O}+\mathrm{O}+\mathrm{O}_{2}+\mathrm{M} \\
\mathrm{O}_{2}^{-}+\mathrm{O}_{2}^{+}+\mathrm{M} \rightarrow \mathrm{O}_{2}+\mathrm{O}_{2}+\mathrm{M}
\end{gathered}
$$

However, if oxygen dissociation degree is high, negative ions will be effectively destroyed in collisions with atomic oxygen:

$$
\mathrm{O}_{2}^{-}+\mathrm{O} \rightarrow \mathrm{O}_{3}+\mathrm{e}
$$

and recombination will take place in electron-ion mode. Another scenario of ions influence on the oxidation and combustion processes is ionic oxidation chains formation [Zatsepin et al, 2003; Kosarev\&Starikovskii, 2000].

Ionic mechanism, connected with charge transfer in $\mathrm{H}_{2}-\mathrm{O}_{2}$ system was proposed in [Kosarev\&Starikovskii, 2000]:

$$
\begin{aligned}
& \mathrm{O}_{2}+\mathrm{e}^{-}+\mathrm{M} \rightarrow \mathrm{O}_{2}^{-}+\mathrm{M} \\
& \mathrm{H}_{2}+\mathrm{O}_{2}^{-} \rightarrow \mathrm{OH}^{-}+\mathrm{OH}
\end{aligned}
$$




$$
\begin{gathered}
\mathrm{OH}+\mathrm{H}_{2} \rightarrow \mathrm{H}_{2} \mathrm{O}+\mathrm{H} \\
\mathrm{OH}^{-}+\mathrm{H} \rightarrow \mathrm{H}_{2} \mathrm{O}+\mathrm{e}^{-} \\
\mathrm{H}+\mathrm{O}_{2}+\mathrm{M} \rightarrow \mathrm{HO}_{2}+\mathrm{M} \\
\mathrm{OH}^{-}+\mathrm{HO}_{2} \rightarrow \mathrm{H}_{2} \mathrm{O}+\mathrm{O}_{2}+\mathrm{e}^{-}
\end{gathered}
$$

The same mechanism can be constructed for hydrocarbons. The efficiency of such mechanisms is limited by plasma decay (electron-ion and ion-ion recombination), but the mechanism remains very effective at low temperatures because of very low activation energy of ion-molecular reactions.

In [Jiao et al, 2007] absolute cross sections for electron impact ionization of n-butane (n$\mathrm{C}_{4} \mathrm{H}_{10}$ ) as functions of electron energy from 10 to $200 \mathrm{eV}$ have been measured by Fourier transform mass spectrometry. The major ions including the parent ion and eight fragment ions $\mathrm{C}_{2} \mathrm{H}_{3-5}{ }^{+}, \mathrm{C}_{3} \mathrm{H}_{3,5-7^{+}}$and $\mathrm{C}_{4} \mathrm{H}_{9}{ }^{+}$are observed, with the total cross section reaching a maximum of $\sim 1.2 \times 10^{-15} \mathrm{~cm}^{2}$ at $\sim 80 \mathrm{eV}$. It was clearly demonstrated that each ion produces additional radical in the process of charge transfer reactions. The most important process is $\mathrm{H}^{-}$transfer. This process leads to effective generation of additional radicals and unsaturated hydrocarbons.

Thus gas ionization plays two ways during plasma decay. Recombination can lead to formation of molecules and significant heat release to translational degrees of freedom. Competing mechanism is recombination with radicals (atoms) formation or excited particles formation. This mechanism produces less heat but more active radicals in the discharge afterglow. Overall, ionization produces more thermal heat and less radicals than excitation of electronic degrees of freedom of nitrogen and direct dissociation by electron impact [Aleksandrov et al, 2010] and not very effective from the point of view of active radicals formation because of relatively high energy price per radical.

\subsection{Fast gas heating by discharge}

Energy release during plasma decay increases the gas temperature and helps to initiate chemical reaction. The key issue is the rate of energy release. Long relaxation time leads to energy "freezing" in the chemical or internal degrees of freedom.

The model [Aleksandrov et al, 2009] of fast gas heating takes into account the mechanisms of energy release suggested in [Popov, 2001] to describe observations at moderate values of $E / n$. In addition, it considers the channels associated with the excitation of higher excited states of the molecules and with the formation, transformation and recombination of charged particles, which are the processes that become important at high values of $E / n$. The experiments and calculations show that the fraction of the discharge power spent on "fast" gas heating increased from $10 \%$ at $E / n=100 \mathrm{Td}$ to $30-55 \%$ at $E / n=1000 \mathrm{Td}$. This noticeably depended on gas pressure and only slightly on the electron density at $\tau=\tau_{d}$, $n_{e f}$. The effect of pressure was negligible at $E / n=100 \mathrm{Td}$ and became more profound at high $E / n$, at which most of the deposited energy was spent on ionization [Starikovskiy\&Aleksandrov, 2011].

\section{Summary}

Nonequilibrium plasma demonstrates great abilities to control ultra-lean, ultra-fast, lowtemperature flames and becomes an extremely promising technology for a wide range of applications, including aviation GTEs, piston engines, RAMjets, SCRAMjets and detonation 
initiation for pulsed detonation engines. To use nonequilibrium plasma for ignition and combustion, it is necessary to understand the mechanisms of plasma assisted ignition and combustion and to simulate numerically discharge and combustion processes under various conditions.

The analysis of discharge processes shows that the discharge energy can be deposited into desired internal degrees of freedom of molecules when varying the reduced electric field, $\mathrm{E} / \mathrm{n}$, at which the discharge is maintained. The amount of the deposited energy is controlled by other discharge and gas parameters including electric pulse duration, discharge current, gas number density, gas temperature, etc. As a rule, the dominant mechanism of the effect of nonequilibrium plasma on ignition and combustion is associated with the generation of active particles in the discharge plasma. Numerical simulation of discharge processes is based on the solution of the Boltzmann equation for electrons and of the balance equations for active particles. Here, input data are electron-molecule cross sections and rate constants for reactions with excited and charged particles. These data are available for simple molecules such as $\mathrm{N}_{2}, \mathrm{O}_{2}, \mathrm{H}_{2}$, and, to a smaller extent, for simple hydrocarbons. However, little is known about cross sections and rates for complex hydrocarbon molecules. The lack of this information does not seem critical when considering lean and stechiometric mixtures; but this problem is serious for the simulation of ignition of rich mixtures.

For plasma assisted ignition and combustion in air-containing mixtures, the most promising active species are $\mathrm{O}$ atoms and, to a smaller extent, some other neutral atoms and radicals. These active particles are efficiently produced in high-voltage nanosecond pulse discharges due to electron impact dissociation of molecules and due to electron impact excitation of $\mathrm{N}_{2}$ electronic states followed by collisional quenching of these states to dissociate molecules. This mechanism was validated above self-ignition threshold for lean and stoichiometric fueloxygen and fuel-air mixtures at pressures up to $2 \mathrm{~atm}$. It was shown that in a wide range of conditions the optimal $E / n$ from the point of view of atomic oxygen generation is approximately two times higher than the electrical breakdown threshold of the mixture. Excitation of low-energy singlet states of $\mathrm{O}_{2}$ could be efficient in pure oxygen. However, fast quenching of oxygen singlet states by fuel molecules (hydrogen, hydrocarbons) significantly decreases the efficiency of this channel. An addition of $\mathrm{N}_{2}$ leads to a smaller amount of energy spent on the excitation of these states because of the competition with vibrational excitation of $\mathrm{N}_{2}$. Vibrationally-excited particles accelerate the reactions and rate of energy release. This mechanism becomes very important at low temperature conditions when reaction energy thresholds cannot be overcome using translational energy only. Competing process is VT relaxation of the gas, which reduces the chances of long energy-back-coupling chains development. Generation of charged particles in discharge plasmas seems to be inefficient for favoring ignition because the energy cost for ionization is too high and the lifetime of charged particles is too short. Despite of this the ionization and fast plasma recombination remains an important channel of fast volumetric gas heating and can be used for plasma assisted ignition. The major problems of physical and chemical models of plasma assisted combustion are associated with the low-temperature regimes below self-ignition threshold. For this range of parameters there are no validated combustion mechanisms. Uncertainties connected with attempts to extrapolate high-temperature combustion mechanisms to low temperatures are too large. A new, validated mechanism for low temperature hydrocarbon combustion is required for qualitative description of plasma assisted combustion below self-ignition threshold. This problem is still unsolved and requires a lot of efforts. 


\section{Acknowledgements}

The work was partially supported by Russian Foundation for Basic Research under the project "Nonequilibrium plasma thermalization", AFOSR under the project "Fundamental Mechanisms, Predictive Modeling, and Novel Aerospace Applications of Plasma Assisted Combustion", and DOE Combustion Energy Frontiers Research Center.

\section{References}

Adamovich I.V., Macheret S.O., Rich J.W., Treanor C.E., Fridman A.A. In: Molecular Physics and Hypersonic Flows. Ed by M. Capitelli. Kluwer Acad. Publ. 1996. P.85.

Aleksandrov N.L., Kindusheva S.V., Nudnova M.M. and Starikovskiy A.Yu. Mechanism of ultra-fast heating in a nonequilibrium weakly-ionized air discharge plasma in high electric fields. J. Phys. D: Appl. Phys. 43 (2010) 255201 (19pp)

Aleksandrov N.L., Kindysheva S.V., Kosarev I.N., Starikovskaia S.M., Starikovskii A.Yu. Mechanism of ignition by non-equilibrium plasma. Proceedings of the Combustion Institute 32 (2009) 205-212.

Aleksandrov N.L., Kindysheva S.V., Kukaev E.N., Starikovskaya S.M., Starikovskii A.Yu. Simulation of the Ignition of a Methane-Air Mixture by a High_Voltage Nanosecond Discharge. Plasma Physics Reports, 2009, Vol. 35, No. 10, pp. 867-882.

Andreadis D. Scramjet engines enabling the seamless integration of air \& space operations. Pratt \& Whitney Space Propulsion, Hypersonics, West Palm Beach, FL, 2005, http://www.pwrengineering.com/dataresources/TIP_Scramjet_Engines_final.pdf

Anikin N B, Starikovskaia S M and Starikovski A Yu. Oxidation of saturated hydrocarbons under the effect of nanosecond pulsed space discharge. J. Phys. D: Appl. Phys. 39 (2006) 3244-3252

Anikin N.B., Pancheshnyi S.V., Starikovskaia S.M., Starikovskii A.Yu. Air Plasma Production by High-Voltage Nanosecond Gas Discharge. 4 Weakly Ionized Gases Workshop. Anaheim. CA, 2001. AIAA 2001-3088.

Babich L.P. Analysis of a new electron runaway mechanism and record-high runaway electron currents supposedly achieved in dense gas discharges. Sov. Phys. Usp., vol. 48 (10), 2005.

Bak M.S., Kim W., Cappelli M.A. Quenching of Excited Electronic States of Molecular Nitrogen in Nanosecond Pulsed Discharges in Atmospheric Pressure Air. 49th AIAA Aerospace Sciences Meeting including the New Horizons Forum and Aerospace Exposition 4 - 7 January 2011, Orlando, Florida AIAA 2011-1150

Berezhetskaya N.K., Gritsinin S.I., Kop'ev V.A., Kossyi I.A., Popov N.A., Silakov V.P., and Van Wie D. Microwave Discharge As A Method For Igniting Combustion in Gas Mixtures. 43rd AIAA Aerospace Sciences Meeting and Exhibit 10 - 13 January 2005, Reno, Nevada. AIAA 2005-991.

Bezgin L.V., Kopchenov V.I., Starik A.M., and Titova N.S. Numerical Study of Formation of a Detonation Wave in a Supersonic Flow over a Wedge by an $\mathrm{H}_{2}-\mathrm{O}_{2}$ Mixture with Nonequilibrium Excitation of Molecular Vibrations of Reagents. Combustion, Explosion, and Shock Waves, Vol. 42, No. 1, pp. 68-75, 2006 
Bowcutt K., "Hypersonic vehicles," In: AccessScience, McGraw-Hill Companies, 2009, http://www.accessscience.com

Bozhenkov S.A., Starikovskaia S.M., Starikovskii A.Yu. Low Temperature Nonequilibrium Plasma Production for Ignition and Combustion Control in Hypersonic Flow. 38th AIAA/ASME/SAE/ASEE Joint Propulsion Conference \& Exhibition, AIAA 20022065.

Bozhenkov S.A., Starikovskaia S.M., Starikovskii A.Yu. Nanosecond Gas Discharge Ignition of $\mathrm{H}_{2}$ and $\mathrm{CH}_{4}$ Containing Mixtures. Combustion and Flame, 2003. V 133, pp. 133146.

Capitelli M. Molecular Physics and Hypersonic Flows. Kluwer Acad. Publ. 1996. P.85.

Do H., Im S., Cappelli M.A., Mungal M.G. Plasma assisted flame ignition of supersonic flows over a flat wall. Combustion and Flame 157 (2010) 2298-2305.

Dutton J. J. Phys. Chem. Ref. Data 4577 (1975)

Efanov V.M. High-Voltage and High-PRF FID Pulse Generators. FID GmbH. 2011.

Esakov I.I., Grachev L.P., Khodataev K.V., Vinogradov V.A., Van Wie D.M. Efficiency of propane-air mixture combustion assisted by deeply undercritical MW discharge in cold high-speed airflow, AIAA-2006-1212, 44th AIAA Aerospace Sciences Meeting and Exhibit, Reno, Nevada, USA, 9-12 January 2006.

Fridman A.A. Plasma Chemistry. Cambridge University Press. 2008.

Fry R.S. A Century of Ramjet Propulsion Technology Evolution. Journal of propulsion and power. Vol. 20, No. 1, January-February 2004.

Grisch F., Grandin G.-A., Messina D., Attal-Trétout B., Laser-based measurements of gasphase chemistry in non-equilibrium pulsed nanosecond discharges Comptes Rendus Mecanique 337 (2009) 504-516

Hayashi M., in: Pitchford L.C., McCoy B.V., Chutjian A., Trajmar S. (Eds.), Swarm Studies and Inelastic Electron-Molecule Collisions, Springer-Verlag, New York, 1987, pp. 167-187.

Huxley L.G.H. and Crompton R.W. The Diffusion and Drift of Electrons in Gases (New York: Wiley-Interscience) 1974.

Ionin A.A., Kochetov I.V., Napartovich A.P., Yuryshev N.N., J. Phys. D Appl. Phys. 40 (2007) R25-R61.

Jiao C Q, DeJoseph Jr C A and Garscadden A. Electron impact ionization and ion reactions in n-butane. J. Phys. D: Appl. Phys. 40 (2007) 409-414 doi:10.1088/00223727/40/2/018

Kof L.M., Starikovskii A.Yu. Gas-phase ignition initiation by high-voltage ionization wave. XI Russian Combustion Symposium. Chernogolovka. 1996.

Kof L.M., Starikovskii A.Yu. Oxygen-Hydrogen Mixtures Ignition under the High-Voltage Ionization Wave Conditions at High Temperatures. 26th International Symposium on Combustion, 1996. WIP Poster Session: Ignition \& Extinction. R.05-052.

Kosarev I., Aleksandrov N., Kindysheva S., Starikovskaia S., Starikovskii A. Kinetics of ignition of saturated hydrocarbons by nonequilibrium plasma: $\mathrm{C}_{2} \mathrm{H}_{6}-$ to $\mathrm{C}_{5} \mathrm{H}_{12}-$ containing mixtures, Combustion and Flame, 156, 221-233 (2009). 
Kosarev I.N., Aleksandrov N.L., Kindysheva S.V., Starikovskaia S.M. and Starikovskii A.Yu. Kinetic mechanism of plasma-assisted ignition of hydrocarbons. J. Phys. D: Appl. Phys. 41 No 3 (7 February 2008) 032002.

Kosarev I.N., Sagulenko P.N., Khorunzhenko V.I., Starikovskaia S.M. Development of DBD surface nanosecond discharge. Proc. of Int. Symp. on Plasma Chemistry (ISPC), 2009.

Kosarev I.N., Starikovskii A.Yu. Mechanism for Electric Breakdown in a Chemically Nonequilibrium System and the Influence of the Chain Oxidation Reaction in an $\mathrm{H}_{2}$-Air Mixture on the Breakdown Threshold. Plasma Physics Reports, 2000. V.26. N.8. P.701.

Kosarev I.N., Aleksandrov N.L., Kindysheva S.V., Starikovskaia S.M., Starikovskii A.Yu. Kinetics of ignition of saturated hydrocarbons by nonequilibrium plasma: $\mathrm{CH}_{4}$ containing mixtures, Combustion and Flame, 154, 569-586 (2008).

Kossyi I.A., Kostinsky A.Yu., Matveyev A.A. and Silakov V.P. Kinetic scheme of the nonequilibrium discharge in nitrogen-oxygen mixtures. PSST. 12071992

Kovach E.A., Losev S.A., Sergievskaia A.L., Khrapak N.A. Models for Physical-Chemical Processes. 3. Thermally-equilibrium and Nonequilibrium Chemical Reactions. Physical-Chemical Kinetics in Gasdynamics. MSU. 2010.

Leonov S.B., Firsov A. A., Yarantsev D. A., Bolshov M. A., Kuritsyn Yu. A., Liger V. V., Mironenko V. R. Dynamics of $\mathrm{H}_{2} \mathrm{O}$ Temperature and Concentration in Zone of Plasma-Assisted High-Speed Combustion. 49th AIAA Aerospace Sciences Meeting including the New Horizons Forum and Aerospace Exposition 4 - 7 January 2011, Orlando, Florida AIAA 2011-972.

Light G.C., Matsumoto J.H. // Chem.Phys.Letters. 1978. V.58. N.4. P 578-581.

Losev S.A., Sergievskaia A.L., Rysanov V.D., Fridman A.A., Macheret S.O. Reports of Russian Academy of Science. 1996. V.346. N 2. P.192.

Macheret S.O., Fridman A.A., Adamovich I.V., Rich J.W., Treanor C.E.// AIAA-Paper 19941984. 1994.

Michael J.B., Dogariu A., Shneider M.N., and Miles R.B., "Subcritical microwave coupling to femtosecond and picosecond laser ionization for localized, multipoint ignition of methane/air mixtures" Journal of Applied Physics. Volume: 108. Issue: 9. Article Number: 093308. NOV 12010.

Nikipelov A.A., Rakitin A.E., Popov I.B., Correale G., Starikovskii A.Yu. Plasmatrons Powered By Pulsed High-Voltage Nanosecond Discharge For Ultra-Lean Flames Stabilization. 49th AIAA Aerospace Sciences Meeting including the New Horizons Forum and Aerospace Exposition 4 - 7 January 2011, Orlando, Florida. AIAA 20111214.

Pai, D.Z., Stancu, G.D., Lacoste, D.A., and Laux, C.O. Plasma Sources Sci. Technol., 18(4) 045030, 2009

Pancheshnyi S. , Nudnova M., Starikovskii A., Development of a cathode-directed streamer discharge in air at different pressures: experiment and comparison with direct numerical simulation, Phys. Rev. E, 71, 016407 (1-12) (2005). 
Pancheshnyi S.V., Starikovskaia S.M., Starikovskii A.Yu. Dynamics of population of electronic levels of molecular nitrogen and structure of fast ionization wave. Plasma Physics Reports, 1999. V.25 N.4 P.326.

Park C. Two-Temperature Interpretation of Dissociation Rate Data for N2 and O2. AIAAPaper 1988-0458. 1988.

Pilla G., Galley D., Lacoste D., Lacas F., Veynante D., Laux C.O., Stabilization of a turbulent premixed flame using a nanosecond repetitively pulsed plasma, IEEE Trans. on Plasma Science, 34(6), 2471-2477 (2006).

Polak L.S. Plasma Chemistry. Cambridge International Science Publishing. 1998.

Popov N.A. Effect of a Pulsed High-Current Discharge on Hydrogen-Air Mixtures. Plasma Physics Reports, 2008, vol. 34, No. 5, pp. 376-391.

Popov N.A. The effect of nonequilibrium excitation on the ignition of hydrogen-oxygen mixtures. High Temp. 45 (2007) 261-279

Popov N.A., Investigation of the mechanism for rapid heating of nitrogen and air in gas discharges Plasma Phys.Rep. 27886 (2001)

Raizer Y.P. Gas Discharge Physics. Springer; Corrected edition (September 19, 1991)

Rakitin A.E., Popov I.B., Starikovskii A.Yu. Detonation Initiation by a Gradient Mechanism in Propane-Oxygen and Propane-Air Mixtures. 49th AIAA Aerospace Sciences Meeting including the New Horizons Forum and Aerospace Exposition 4 - 7 January 2011, Orlando, Florida. AIAA 2011-586.

Rakitin A.E., Starikosvkii A.Yu. Mechanisms of Deflagration-to-Detonation Transition under Initiation by High-Voltage Nanosecond Discharges, Combustion and Flame, 155, 343-355 (2008).

Roupassov D., Nudnova M., Nikipelov A., Starikovskii A. Sliding DBD for Airflow Control: Structure and Dynamics. 46th AIAA Aerospace Sciences Meeting and Exhibit 7 - 10 Jan 2008 Grand Sierra Resort Hotel Reno, Nevada. Paper AIAA-2008-1367.

Rusanov V.D., Fridman A.A. Physics of Chemically-Active Plasma. Nayka, Moscow. 1985.

Sagulenko P.N., Khorunzhenko V.I., Kosarev I.N. Ignition by nanosecond surface discharge. 8th Int. Workshop on Magneto-Plasma Aerodynamics, March 31-April 2, 2009, Moscow, Russia

Serbin S., Mostipanenko A., Matveev I., Tropina A. Improvement of the Gas Turbine Plasma Assisted Combustor Characteristics. 49th AIAA Aerospace Sciences Meeting including the New Horizons Forum and Aerospace Exposition 4 - 7 January 2011, Orlando, Florida AIAA 2011-61.

Shibkov V M, Aleksandrov A F, Chernikov V A, Ershov A P, Konstantinovskij R S and Zlobin V V 2006 Combined MW-DC discharge in a high speed propane-butane-air stream 44th AIAA Aerospace Sciences Meeting and Exhibit (Reno, Nevada, USA, 2006) AIAA-2006-1216

Singleton D., Pendleton S.J. and Gundersen M.A. The role of non-thermal transient plasma for enhanced flame ignition in $\mathrm{C}_{2} \mathrm{H}_{4}$-air. J. Phys. D: Appl. Phys. 44 (2011) 022001

Smirnov V.V., Stelmakh O.M., Fabelinsky V.I., Kozlov D.N., Starik A.M. and Titova N.S. On the influence of electronically excited oxygen molecules on combustion of hydrogen-oxygen mixture. J. Phys. D: Appl. Phys. 41 (2008) 192001 (6pp) 
Stancu G.D., Kaddouri F., Lacoste D.A., and Laux C.O. Atmospheric pressure plasma diagnostics by OES, CRDS and TALIF. J. Phys. D: Appl. Phys. 43 (2010) 124002 (10pp)

Starikovskaia S M, Starikovskii A Yu. Plasma assisted ignition and combustion. In: Handbook of Combustion, by Maximilian Lackner (Ed.), Franz Winter (Ed.), Avinash K. Agarwal (Ed.), Wiley-VCH, ISBN: 978-3527324491 (2010).

Starikovskaia S.M., Plasma assisted ignition and combustion, J. Phys. D. Appl. Phys. 39 (2006) 265-299.

Starikovskaia S.M., Kukaev E.N., Kuksin A.Yu., Nudnova M.M., Starikovskii A.Yu. Analysis of the spatial uniformity of the combustion of a gaseous mixture initiated by a nanosecond discharge, Combustion and Flame 139 177-187 (2004).

Starikovskii A.Yu. Plasma Supported Combustion. Proceedings of the Combustion Institute, Volume 30, Issue 2, January 2005, Pages 2405-2417.

Starikovskii A.Yu. State-to-State Chemical Reaction Rate Constants: Vibronic Terms Approximation. Physical and Chemical Kinetics in Gas Dynamics. 2003. V 1. http://www.chemphys.edu.ru/pdf/2003-12-25-001.pdf

Starikovskii A.Yu., Anikin N.B., Kosarev I.N., Mintoussov E.I., Starikovskaia S.M., and Zhukov V.P. Plasma-assisted combustion. Pure Appl. Chem., Vol. 78, No. 6. 2006.

Starikovskii A.Yu., Plasma supported combustion, Proc. Comb. Inst. 30 (2005) 2405-2417.

Starikovskiy A.Yu., Aleksandrov N.L. Nonequilibrium Plasma Aerodynamics. In: "Aeronautics and Astronautics", ISBN 978-953-307-473-3. InTech, 2011

Starikovskiy A.Yu., Rakitin A.E., Pancheshnyi S.V. Periodic Pulse Discharge Self-Focusing and Streamer-to-Spark Transition in Under-Critical Electric Field. 49th AIAA Aerospace Sciences Meeting. Orlando, Florida. Jan 2011. Paper AIAA-2011-1271.

Tachibana K., Phys. Rev. A 34 (1989) 1007-1015.

Uddi M., Guo H., Sun W., Ju Y. Studies of $\mathrm{C}_{2} \mathrm{H}_{6} /$ air and $\mathrm{C}_{3} \mathrm{H}_{8}$ /air Plasma assisted combustion kinetics in a nanosecond discharge. 49th AIAA Aerospace Sciences Meeting including the New Horizons Forum and Aerospace Exposition 4 - 7 January 2011, Orlando, Florida AIAA 2011-970

Wu L., Fridman A.A. and Starikovskiy A.Yu. Kinetics of Plasma Assisted Combustion At Low Reduced Electric Fields. 48th AIAA Aerospace Sciences Meeting including the New Horizons Forum and Aerospace Exposition 4 - 7 January 2010, Orlando, Florida AIAA 2010-1593

Wu L., Lane J., Cernansky N., Miller D., Fridman A. and Starikovskiy A. Time resolved PLIF and $\mathrm{CRD}$ diagnostics of $\mathrm{OH}$ radicals in the afterglow of plasma discharge in hydrocarbon mixtures. 7th US National Combustion Meeting. March 20-23, 2011.

Wu L., Lane J., Cernansky N.P., Miller D.L., Fridman A.A. and Starikovskiy A.Yu. Plasma Assisted Ignition Below Self-Ignition Threshold In Methane, Ethane, Propane And Butane-Air Mixtures. Proceedings of the Combustion Institute 33 (2010)

Zatsepin D.V., Starikovskaia S.M., Starikovskii A.Yu. Hydrogen oxidation in a stoichiometric hydrogen-air mixtures in the fast ionization wave. Combust. Theory Modeling, 2001. V.5 pp.97-129. 
Zatsepin D.V., Starikovskaia S.M., Starikovskii A.Yu. Non-Thermal Decomposition of $\mathrm{N}_{2} \mathrm{O}$ in Pulsed High Current Discharge. Plasma Physics Reports, 2003. V 29, N 6, pp. 517-527. 


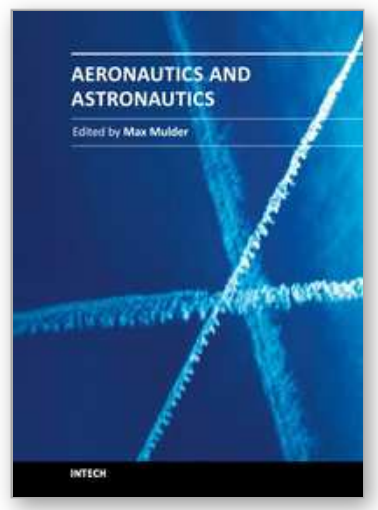

\author{
Aeronautics and Astronautics \\ Edited by Prof. Max Mulder
}

ISBN 978-953-307-473-3

Hard cover, 610 pages

Publisher InTech

Published online 12, September, 2011

Published in print edition September, 2011

In its first centennial, aerospace has matured from a pioneering activity to an indispensable enabler of our daily life activities. In the next twenty to thirty years, aerospace will face a tremendous challenge - the development of flying objects that do not depend on fossil fuels. The twenty-three chapters in this book capture some of the new technologies and methods that are currently being developed to enable sustainable air transport and space flight. It clearly illustrates the multi-disciplinary character of aerospace engineering, and the fact that the challenges of air transportation and space missions continue to call for the most innovative solutions and daring concepts.

\title{
How to reference
}

In order to correctly reference this scholarly work, feel free to copy and paste the following:

Andrey Starikovskiy and Nickolay Aleksandrov (2011). Plasma-Assisted Ignition and Combustion, Aeronautics and Astronautics, Prof. Max Mulder (Ed.), ISBN: 978-953-307-473-3, InTech, Available from:

http://www.intechopen.com/books/aeronautics-and-astronautics/plasma-assisted-ignition-and-combustion

\section{INTECH}

open science | open minds

\section{InTech Europe}

University Campus STeP Ri

Slavka Krautzeka 83/A

51000 Rijeka, Croatia

Phone: +385 (51) 770447

Fax: +385 (51) 686166

www.intechopen.com

\section{InTech China}

Unit 405, Office Block, Hotel Equatorial Shanghai

No.65, Yan An Road (West), Shanghai, 200040, China

中国上海市延安西路 65 号上海国际贵都大饭店办公楼 405 单元

Phone: +86-21-62489820

Fax: +86-21-62489821 
(C) 2011 The Author(s). Licensee IntechOpen. This chapter is distributed under the terms of the Creative Commons Attribution-NonCommercialShareAlike-3.0 License, which permits use, distribution and reproduction for non-commercial purposes, provided the original is properly cited and derivative works building on this content are distributed under the same license. 